N-Cadherin is a Prospective Cell Surface Marker of Human Mesenchymal Stem Cells that Have High Ability for Cardiomyocyte Differentiation

January 2014

Hisako ISHIMINE 


\title{
N-Cadherin is a Prospective Cell Surface Marker of Human Mesenchymal Stem Cells that Have High Ability for Cardiomyocyte Differentiation
}

\author{
A Dissertation Submitted to \\ the Graduate School of Life and Environmental Sciences, \\ the University of Tsukuba \\ in Partial Fulfillment of the Requirements \\ for the Degree of Doctor of Philosophy in Science \\ ( Doctoral Program in Biological Sciences )
}

Hisako ISHIMINE 


\section{Table of Contents}

Table of contents • • • • • • • • • • • • i

I .Abstract • • • • • • • • • • • • • • 1

II Abbreviations • • • • • • • • • • • • • • •

III.Introduction • • • • • • • • • • • • • • 5

III-1. Cardiac disease

III-2. Stem cell therapy for cardiac disease

III-3. Object of this study and research plan

IV. Materials and methods

IV-1. Cells

IV-2. Preparation of mouse fetal cardiomyocytes

IV-3. Cardiac differentiation of human MSCs by co-culturing with mouse fetal cardiomyocytes

IV-4. Immunofluorescence staining

IV-5. Immunoblotting analysis

IV-6. Flow cytometric analysis

IV-7. Magnetic cell sorting enrichment of N-cadherin-positive populations 
IV-8. DNA microarray analysis

IV-9. Quantitative RT-PCR

IV-10. Statistical analysis

V. Results • • • • • • • • • • • • • • 20

V-1 Exploration for prospective cell surface marker

V -1.1. Differentiation efficiency of MSC lines into cardiomyocytes

V -1.2. Expression analysis of N-cadherin in MSCs and correlation with the differentiation efficiency toward beating cardiomyocytes

V-1.3.Differentiation efficiency of primary MSCs into cardiomyocytes and correlation with expression of $\mathrm{N}$-cadherin

V-2 Magnetic cell sorting by $\mathrm{N}$-cadherin expression

V-2.1. Demonstration of magnetic cell sorting

V -2.2. Magnetic cell sorting of hMSCs and their differentiation ability

$\mathrm{V}$-2.3. Characterization of $\mathrm{N}$-cadherin positive cells

VI. Discussion • • • • • • • • • • • • • 31

VII. Acknowledgements • • • • • • • • • • • • 36

VIII. References • • • • • • • • • • • • • 37

IX. Table • • • • • • • • • • • • • 49

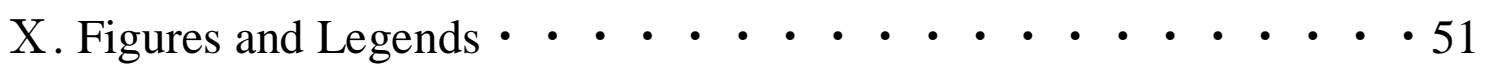




\section{I . Abstract}

Mesenchymal stem cells (MSCs) are among the most promising sources of stem cells for regenerative medicine. However, their range of differentiation ability is very limited. MSCs readily differentiate into osteoblasts, chondrocytes, and adipocytes in vitro, but do not differentiate into cells of other tissues, such as cardiomyocytes with high efficiency. In this study, we attempted to determine prospective cell surface markers of human MSCs that readily differentiate into cardiomyocytes. The cardiomyogenic differentiation potential and the expression of cell surface markers involved in heart development were analyzed using various immortalized human MSC lines, and MSCs with high expression of N-cadherin showed a higher probability of differentiation into beating cardiomyocytes. The differentiated cardiomyocytes expressed terminally differentiated cardiomyocyte-specific markers such as $\alpha$-actinin, cardiac troponin $\mathrm{T}$, and connexin-43. A similar correlation was observed with primary human MSCs derived from bone marrow and adipose tissue. Moreover, $\mathrm{N}$-cadherin-positive MSCs isolated using $\mathrm{N}$-cadherin antibody-conjugated magnetic beads showed an apparently higher capacity for differentiation into cardiomyocytes than did the N-cadherin-negative population. Gene ontology analysis of global gene expression in these populations suggested that N-cadherin-positive MSCs selectively 
up-regulated nuclear proteins involved in transcription. Results of quantitative polymerase chain reaction ( $\mathrm{qPCR}$ ) analyses demonstrated that the $\mathrm{N}$-cadherin-positive population expressed significantly elevated messenger ribonucleic acid (mRNA) levels of cardiomyogenic progenitor-specific transcription factor genes, including $N k x 2.5$, Hand1, and GATA4, and pluripotency-related genes such as Pou5f1 (Oct4), Sall4, and Nanog. Our results suggest that $\mathrm{N}$-cadherin is a novel prospective cell surface marker of human MSCs that show a better ability for cardiomyocyte differentiation; these MSCs are characterized by an up-regulated expression of transcription factors specific to cardiomyogenic progenitors. 


\section{II . Abbreviations}

APC: allophycocyanin

ASCs: adipose-derived stem cells

BMSCs: bone marrow-derived MSCs

Cn43: connexin-43

CPCs: cardiac progenitor cells

cTnT: cardiac troponin T

DMEM: Dulbecco’s Eagle Medium

ECL: Enhanced chemiluminescence

EDTA: ethylenediaminetetraacetic acid

EGFP: enhanced green fluorescent protein

EGM: endothelial cells growth media

ES: embryonic stem

FCS: fetal calf serum

GM-CSF: granulocyte-macrophage colony-stimulating factor

HEK: Human embryonic kidney

HUVEC: Human umbilical vein endothelial cells

iPS: induced pluripotent stem 
LVEF: left ventricular ejection fraction

MACS: magnetic cell sorting

MI: myocardial infarction

MSCs: Mesenchymal stem cells

Oct4: Pou5f1

PBS: phosphate-buffered saline

Pdgfra: Platelet-derived growth factor receptor $\alpha$

PI: propidium iodide

qPCR: Quantitative polymerase chain reaction

RNA: ribonucleic acid

Reverse Transcription: RT

TBS: Tris-buffered saline

VCAM-1: vascular cell adhesion molecule 1

VEGFR: vascular endothelial growth factor receptor 


\section{Introduction}

\section{III-1. Cardiac disease}

Myocardial infarction (MI) caused by atherosclerosis of the coronary artery induces heart failure with high mortality. Atherosclerotic plaques lead to coronary artery stenosis and a reduction in the blood flow rate, thereby contributing to cardiac ischemia and necrosis. The injured cardiomyocytes are replaced by fibroblasts; this then leads to fibrosis. The injured left ventricle undergoes progressive chamber dilation. Because the myocardium has very limited regeneration ability, an injured heart cannot be repaired. Heart transplantation is currently considered the most effective treatment for severe heart failure. Although artificial hearts can be used until heart transplantation is possible, the current devices are not suitable for long-term use, and antithrombogenicity, biocompatibility, reliability, and durability of these devices need to be improved. Another serious concern for the clinical application of this methodology is the limited number of donors for heart transplantation. Therefore, stem cell therapy is expected to be an alternative regenerative medicine for heart failure.

\section{III-2. Stem cell therapy for cardiac disease}

Some types of stem cells can be considered useful for cardiac regeneration in 
clinical trials. Human embryonic stem (ES) cells can differentiate into cardiomyocytes when exposed to activin A and bone morphogenic protein 4. (Laflamme et al., 2007). ES cells are pluripotent cells derived from the inner cell mass of blastocyst-stage embryos therefore these are not the optimal choice for clinical application. Human dermal fibroblast can be induced to become pluripotens stem cells by retroviral transduction of four transcription factors, viz., OCT3/4, SOX2, c-MYC, and KLF4 (Takahashi et al., 2007). These induced pluripotent stem (iPS) cells circumvent many of the ethical issues surrounding ES cells. However, generating large numbers of autologous cardiomyocytes within a therapeutic time-frame remains challenging. Intramyocardial injections of skeletal myoblasts result in arrhythmias occurred (Leobon, 2003). Because of these discouraging results, a decline in skeletal myoblast studies has been observed in recent years. Cardiac progenitor cells (CPCs) have also been used in clinical trials. These cells can be isolated from cardiac tissue obtained during heart surgery or by endocardial biopsy. Results from one of the trials demonstrated a $12.3 \%$ improvement in left ventricular ejection fraction (LVEF) in patients at 1 year after intracoronary injection of autologous c-kit ${ }^{+}$, lineage- CPCs following after MI (Bolli et al. 2011). MSCs have also been shown to be suitable candidates to repair cardiac injury post-MI. Under appropriate stimulation, MSCs can differentiate into myocytes, 
endothelial cells, and smooth muscle cells in the infarcted heart (Kajstura et al., 2005).

MSCs have been shown to differentiate into various cell types, including osteoblasts, chondrocytes, adipocytes, neurons, and skeletal and cardiac muscle cells in vitro. Results from recent studies have suggested that the delivery of adult MSCs into ischemic tissue augments the recovery of cardiac function after ischemia in vivo (Chen et al., 2004). However, the effects induced by MSCs were only effectual immediately after acute MI. Moreover, the successful differentiation of transplanted MSCs in vivo was quite infrequent, and the rarely observed differentiated cells in host tissues were mainly produced by cell fusion between the injected MSCs and differentiated host cells (Nygren et al., 2004). Therefore, the beneficial effects of MSCs may be attributed to the paracrine effects of various trophic factors transiently secreted by the injected stem cells (Caplan et al., 2011). These results suggest that improvements in the differentiation abilities of MSCs and their successful engraftment could be beneficial for effective treatment of heart failure.

\section{III-3. Objective of this study and research plan}

MSCs can differentiate into many different cell lineages. However the efficiecny of their differentiation into cardiomyocytes is very low (Shiota et al., 2007; 
Wakitani et al., 1995; Makino et al. 1999). To overcome this problem, we tried to determine prospective cell surface markers that could be used to isolate human MSCs with higher cardiomyogenic differentiation potential.

During early embryogenesis, heart development can be monitored by the expression of a homeobox-containing transcription factor, $\mathrm{Nkx} 2.5$, which is expressed in the cardiomyogenic mesoderm at E7.5 in mouse embryos (Lints et al., 1993). The Nkx2.5-positive progenitor cells have a bi-potential character, and they subsequently differentiate into both cardiac and smooth muscle cells (Wu et al., 2006). Another transcription factor, Isl-1, which has two N-terminal LIM domains and one C-terminal homeodomain, is expressed in the splanchnic mesoderm at a similar stage (E7.5) (Cai et al., 2003). Isl-1-positive progenitors are tri-potential progenitor cells, and they differentiate into cardiomyocytes, endothelial cells, and smooth muscle cells (Moretti A. et al., 2006, Laugwitz et al., 2005).

Flk1, a vascular endothelial growth factor receptor (VEGFR) 2, has been reported to be prospective cell surface marker of cardiomyocyte progenitor cells during heart development (Kattman et al., 2006, Yamashita et al., 2005, Ema et al., 2006). Flk1 is expressed in the progenitors of multiple mesodermal lineages, including cardiac, endothelial, and vascular smooth muscle cells (Kattman et al., 2006). c-Kit (CD117 
antigen) is a transmembrane tyrosine kinase receptor for stem-cell factor, and is used as a cell surface marker of hematopoietic progenitors, melanocytes, mast cells, and spermatogonial stem cells. c-Kit is also required for terminal differentiation of cardiomyocytes (Li et al., 2008). Recent research has suggested that c-kit could be a putative cell surface marker of cardiomyogenic progenitor cells in the neonatal heart (Tallini et al., 2009).

$\mathrm{A} \mathrm{Ca}^{2+}$-dependent cell-cell adhesion molecule (Figure 1), N-cadherin is also expressed on cardiomyocyte progenitor cells during mouse development (Figure 1). $\mathrm{N}$-Cadherin expression is observed in the precardiac mesoderm at E8.5 in mice and continues to be expressed in the whole heart during development. N-Cadherin-knockout mice die by E10 because of defects in the primitive heart. Although myocardial tissue was initially formed in the knockout mouse embryos, the myocytes subsequently became dissociated, and the heart tube failed to develop (Radice et al., 1997).

In this study, we studied cell surface markers of human MSCs that have a high ability to differentiate into cardiomyocytes. We show that $\mathrm{N}$-cadherin is a prospective cell surface marker of MSCs with high cardiomyogenic potential. 


\section{Materials and methods}

\section{IV-1. Cells used in this study}

Human MSC lines, namely, UE7T-13 (JCRB1154), UE6E7T-11 (JCRB1149), UBE6T-15 (JCRB1159), UE6E7T-12 (JCRB1151), UE7T-9 (JCRB1147), and UE6E7T-2 (JCRB1133), were obtained from the Japanese Collection of Research Bioresources Cell Bank (Osaka, Japan). These cell lines were immortalized by retrovirus gene transfer of a combination of $b m i-1, E 6, E 7$, and/or TERT genes to human bone marrow stromal cells harvested from a 91-year-old woman. The EPC-214 cell line was similarly immortalized at the National Research Institute for Child Health and Development (NRICHD), Tokyo, Japan. These cells were maintained in Dulbecco's Eagle Medium (DMEM) with high glucose (Wako) supplemented with $10 \%$ fetal calf serum (FCS; Roche). ANP0425 and 0607NC cells derived from human bone marrow were obtained from Dr. Ohgushi (National Institute of Advanced Industrial Science and Technology, Hyougo, Japan). MSC-R36_2 cells, MSC-R36_3 cells, and Yub623 cells were obtained from the RIKEN BRC Cell Bank (Ibaraki, Japan). KN-SC (KN) cells, MY-SC (MY) cells, and NN-SC (NN) cells were prepared at the Research Institute National Center for Global Health and Medicine (NCGM), Tokyo, Japan. Adipose-derived stem cells (ASCs), including 09-036 (36) cells, 10-008 (8) cells, 
05-055 (55) cells, and 05-076 (76) cells, were prepared at the University of Tokyo, School of Medicine, Tokyo, Japan. Other human ASCs were purchased from Invitrogen. For MSCs obtained from adipose tissue, all samples except $\mathrm{KN}-\mathrm{SC}$ were obtained from women aged 22-45 years (KN-SC_was derived from the adipose tissue of a 41-year-old man). All of these primary cells were maintained in MesenPRO RS Basal Medium supplemented with MesenPRO RS Growth Supplement (GIBCO). Cells were maintained in a humidified incubator at $37{ }^{\circ} \mathrm{C}$ with an atmosphere of $5 \% \mathrm{CO}_{2}$. All the experiments using human materials were approved by the Human Ethics Committee at AIST, NRICHD, NCGM, and the University of Tokyo. Human umbilical vein endothelial cells (HUVEC) were cultured in RPMI-1640 medium supplemented with endothelial cells growth media (EGM)-2 SingleQuots (LONZA) and penicillin/streptomycin (Wako). TF-1 cells were cultured in RPMI-1640 supplemented with $10 \%$ FCS, $2 \mathrm{ng} / \mathrm{mL}$ rh granulocyte-macrophage colony-stimulating factor (GM-CSF), and penicillin/streptomycin (Wako). Human embryonic kidney (HEK) 293FT cells were cultured in DMEM medium supplemented with $10 \%$ FCS, $2 \mathrm{mM}$ L-glutamine, $100 \mu \mathrm{M}$ Non-Essential Amino Acids and penicillin/streptomycin (Wako). 


\section{IV-2 Preparation of mouse fetal cardiomyocytes}

Fetal cardiomyocytes were obtained from the hearts of fetal ICR mice on gestation day 16.5. The fetal hearts were cut into small pieces and washed with phosphate-buffered saline (PBS). They were incubated with $0.15 \%$ trypsin and $0.012 \%$ ethylenediaminetetraacetic acid (EDTA) in PBS at $37{ }^{\circ} \mathrm{C}$ for $10 \mathrm{~min}$ under gentle stirring. The supernatant containing the dissociated cardiomyocytes was mixed with DMEM supplemented with $10 \%$ FCS and centrifuged at 1,000rpm (180g) for $5 \mathrm{~min}$. The pellet was then re-suspended in $10 \mathrm{~mL}$ of DMEM with $10 \%$ FCS and incubated in a glass dish for $1 \mathrm{~h}$ to remove fibroblasts. The floating cardiomyocytes were collected and re-plated at $5 \times 10^{5} / \mathrm{cm}^{2}$ on gelatin-coated glass bottom dishes (Asahi Techno Glass). All the experiments using animals were performed under the guidelines established by the University of Tsukuba Animal Use and approved by the Animal Experiment Committee at AIST.

IV-3 Cardiac differentiation of human MSCs by co-culturing with mouse fetal cardiomyocytes

HEK293FT cells were transiently transfected with an enhanced green fluorescent protein (EGFP)-expressing lentivirus vector, CS-RfA-EG (a kind gift from 
Dr. Miyoshi, Riken) and plasmids encoding gag/pol, rev, and VSV-G (ViraPower Lentivirus Expression System, Invitrogen) by using Lipofectamine 2000 (Invitrogen). At $72 \mathrm{~h}$ post-transfection, the supernatant was filtered through a $0.45-\mu \mathrm{m}$ filter, and the EGFP virus was concentrated using a Lenti-X-concentrator (Clontech). Human MSCs were infected with the EGFP lentivirus in the presence of $8 \mu \mathrm{g} / \mathrm{mL}$ of polybrene. Two days later, EGFP-expressing MSCs were harvested with $0.25 \%$ trypsin and $1 \mathrm{mM}$ EDTA and seeded onto the cultured fetal cardiomyocytes at $7 \times 10^{4} / \mathrm{cm}^{2}$. Every 2 days, the culture medium was replaced with fresh culture medium that was supplemented with $10 \%$ FCS. The morphology of the beating EGFP-labeled MSCs was evaluated using a fluorescence microscope. Microscopic images were monitored using an Olympus IX70 microscope equipped with CoolSNAP HQ2 (Photometrics), processed using MetaMorph software (Molecular Devices), and stored as digital video files. The periodical contraction recorded in the video files was further analyzed using Motion Analyzer software (Keyence Corp, Japan). The quantification of the contracting EGFP-positive human MSCs was performed by counting the beating cardiomyocytes in whole wells under a fluorescence microscope. There are many more beating GFP-positive cardiomyocytes than shown in our quantified data. However, GFP-positive cells that could potentially be pulled by the adjacent mouse 
cardiomyocytes were not counted. The data were obtained from at least two independent experiments.

\section{IV-4. Immunofluorescence staining}

Human MSC lines, EPC-214, UE7T-13, UE6E7T-11, UBE6T-15, UE6E7T-12, UE7T-9, and UE6E7T-2 were cultured in Lab-Tek Chamber Slides (Nunc). The cells were fixed in 4\% paraformaldehyde/Tris-buffered saline (TBS), blocked in TBS containing 5\% donkey serum and $0.25 \%$ Tween-20 for $60 \mathrm{~min}$ at.room temperature, and further incubated overnight at $4{ }^{\circ} \mathrm{C}$ with the antibodies against the following proteins: N-cadherin (C3865, Sigma, 1:100), $\alpha$-actinin (A7811, Sigma, 1:100), connexin-43 (C6219, Sigma, 1:1000), and cardiac troponin T (cTnT; MS-295, NeoMarkers, 1:200). These primary antibodies were diluted with TBS containing 5\% donkey serum and $0.25 \%$ Tween-20. Subsequently, the cells were washed three times in TBS. Alexa594-conjugated secondary antibody was applied to visualize expression of specific proteins. The images were obtained using an Olympus IX70 microscope equipped with CoolSNAP HQ2 (Photometrics) and processed using MetaMorph software (Molecular Devices). Confocal images of the differentiated cells were captured sequentially for GFP (excitation: $473 \mathrm{~nm}$, emission range: 490-540 nm) and Alexa 
Fluor 594 (excitation: $559 \mathrm{~nm}$, emission range: 575-675 nm) using an Olympus FluoView FV1000 confocal microscope. After sequential excitation, green and red fluorescent images of the same cells were saved and analyzed with FluoView software (Ver. 1.7).

\section{IV-5. Immunoblotting analysis}

Human mesenchymal stem cell lines, EPC-214, UE7T-13, UE6E7T-11, UBE6T-15, UE6E7T-12, UE7T-9, and UE6E7T-2 were homogenized in a buffer containing $20 \mathrm{mM}$ Tris- $\mathrm{HCl}(\mathrm{pH}$ 7.4), $300 \mathrm{mM} \mathrm{NaCl}, 0.5 \mathrm{mM}$ EDTA, and 1\% NP-40, and supplemented with complete protease inhibitor cocktail (Roche). After centrifugation at $13,000 \mathrm{rpm}(13,000 \mathrm{~g})$ for $10 \mathrm{~min}$ at $4{ }^{\circ} \mathrm{C}$, the supernatant was collected, and the protein concentration was determined using the Protein Assay Kit (Bio-Rad). Equal amounts of sample were boiled in sample buffer and separated by 5-20\% SDS-PAGE. The blots were incubated with antibodies against N-cadherin (C3865, Sigma, 1:200), Flk1 (10347, IBL, 1:100), c-kit (AF332, R\&D Systems, 1:200), Integrin- $\alpha 4$ (sc-14008, R\&D Systems, 1:200), vascular cell adhesion molecule 1

(VCAM-1; sc-8304, Santa Cruz, 1:200), Platelet-derived growth factor receptor $\alpha$ (PDGFR $\alpha$; 323503, BioLegend, 1:200), Nkx2.5 (sc-14033, Santa Cruz, 1:200), GATA4 
(sc-9053, Santa Cruz, 1:200), or $\beta$-tubulin (RB-9249, NeoMarkers, 1:1000). Proteins were detected using an enhanced chemiluminescence reagent (SuperSignal West Femto Maximum Sensitivity Substrate, Pierce) using an LAS-3000 Image Analyzer (Fuji Film).

\section{IV-6. Flow cytometric analysis}

All of the MSCs cell lines and primary MSCs were harvested with cell dissociation buffer (GIBCO) and blocked with normal sheep IgG on ice for $1 \mathrm{~h}$. Cells were incubated with biotinylated anti-N-cadherin antibody (BAF1388, R\&D System, 1:100), anti-Flk1 antibody (10347, IBL, 1:100), and allophycocyanin (APC)-conjugated anti-c-kit antibody (550412, Becton Dickinson, 1:100) on ice for $1 \mathrm{~h}$. The N-cadherin antibody was fluorescent labeled using APC-Alexa Fluor 750 streptavidin (Molecular Probes). The Flk1 antibody was fluorescently labeled with Alexa Fluor 488-conjugated secondary antibody (Molecular Probes). Cells were resuspended in buffer with propidium iodide (PI) (Sigma). Analysis was performed on the FACS Aria (Becton Dickinson). Data were re-analyzed by FlowJo software (TOMY Digital Biology, Japan). The data was obtained from at least 2 independent experiments. 


\section{IV-7. Magnetic cell sorting enrichment of $\mathbf{N}$-cadherin-positive populations}

Immunomagnetic separation of $\mathrm{N}$-cadherin-positive cells was performed with the autoMACS Pro system (Miltenyi Biotec), according to the manufacturer's recommendations. Primary MSCs derived from adipose tissue were dissociated with cell dissociation buffer (GIBCO) and blocked with normal sheep IgG. MSCs were incubated with biotinylated anti-N-cadherin antibody, followed by incubation with streptavidin-APC. Subsequently, cells were incubated with anti-APC microbeads. Magnetic cell separation was carried out using the autoMACS Pro separator (Miltenyi Biotec) with the Dep1025 separation program, according to the recommendations in the user's manual.

\section{IV-8. DNA microarray analysis}

Total RNA was isolated from N-cadherin-positive or -negative MSCs using ISOGEN (Nippon Gene) according to the manufacturer's recommendations. Fluorescently labeled cRNAs were synthesized using Quick-Amp Labeling Kit (Agilent). Labeled cRNAs were hybridized with the $4 \times 44 \mathrm{k}$ Whole Human Genome oligoMicroarrays (G4122F). The microarray was scanned using a G2505C microarray scanner (Agilent), and the result was analyzed with Feature Extraction Software 
(Agilent). We analyze differences in gene expression among human MSCs and human embryonic stem (ES) cells, with GeneSpring GX 11.5.1 software, (Agilent Technologies). Data obtained from the gene expression analysis has been deposited in GEO (accession number GSE35232). The microarray data of human ES cells (Tesar et al., 2007 ) were obtained from GEO data base (GEO accession No. GSE7900).

\section{IV-9. Quantitative RT-PCR}

Cardiomyocyte-specific gene expression was examined by quantitative reverse transcription (RT)-PCR. Total RNA was extracted from the N-cadherin-positive or -negative MSCs by using ISOGEN (Nippon Gene), according to the manufacturer's instructions, and complementary deoxyribonucleic acids (cDNAs) were synthesized using PrimeScript Reverse transcriptase (TaKaRa). Primers used for the PCRs are listed in Table S1. Real-time PCR reactions were performed using THUNDERBIRD ${ }^{\mathrm{TM}}$ SYBR qPCR Mix (TOYOBO) with the following program: denaturation at $95{ }^{\circ} \mathrm{C}$ for $15 \mathrm{~s}$ and annealing and polymerization at $60{ }^{\circ} \mathrm{C}$ for $30 \mathrm{~s}$; analysis was performed with the Chromo4 system (Bio-Rad). 


\section{IV-10. Statistical analysis}

All experiments were repeated independently at least twice. Statistical significance was determined using a two-tailed Student's $t$-test. Differences were considered significant at $\mathrm{P}<0.05$. The Pearson product-moment correlation coefficient was used as a measure of strength of the linear association between differentiation efficiency and $\mathrm{N}$-cadherin expression. All statistical analysis was performed using the data analysis package included in Microsoft Excel 2007 software. 


\section{Results}

\section{V-1 .Determination of prospective cell surface marker}

\section{V -1.1. Efficiency of differentiation of MSC lines into cardiomyocytes}

MSCs are a mixed cell population of primary adherent cells derived from the stroma of various adult tissues, including the bone marrow and adipose tissue. The multipotency of MSCs significantly decreases during tissue culture, particularly in high serum-containing medium. Therefore, it is not easy to obtain reliable data from these heterogeneous MSCs. To overcome these problems, we took advantage of immortalized human MSC clones expressing bmi-1, TERT, E6, and/or E7, which retain their multipotent differentiation ability over a long time when cultured in vitro (Mori et al., 2005). Using this method, various immortalized cell lines without chromosomal instability, have been established from primary cells. There are several difficulties encountered in culturing cells, such as human ovarian surface epithelial cells, extravillous trophoblast cells, amnion epithelial cells, endometrial glandular cells, hepatocytes, and fibroblasts (Maeda et al., 2005; Omi et al., 2009; Zou et al., 2013; Kyo et al., 2003; Tsuruga et al., 2008; Kamada et al., 2012). For the cardiac differentiation of human MSCs, a DNA demethylating drug, 5-aza-2'-deoxycitydine has been used (Shiota et al, 2007). However, the efficiency of differentiation of MSCs was extremely 
low $(<0.005 \%)$. Recent reports also use a co-culture-based method using primary cardiomyocytes obtained from mouse embryos or new born mice, which shows much better differentiation ability than the former method (Iijima et al., 2003). As for the latter method, human MSC cell lines were first labeled with a GFP-expressing lentivirus and then cultured on a cardiomyocyte feeder cells prepared from mouse embryonic heart tissue (E16.5), as illustrated in Figure 2. Some of the human MSC lines such as EPC-214 and UE7T-13 efficiently differentiated into cardiomyocytes. After 5 days of culture, a small number of GFP-labeled human MSCs spontaneously began to contract. On day 7, 5-10\% of these GFP-labeled MSCs differentiated into beating cardiomyocytes. GFP-positive, differentiated cardiomyocytes showed autonomously periodical contractions (Figure 3). Next, the efficiency of human MSCs differentiation into spontaneously beating cardiomyocytes was quantified by counting the number of GFP-positive and spontaneously beating cardiomyocytes by using a fluorescence microscope on day 7 of differentiation (Figure 4). Immunofluorescence analysis confirmed that a significant number of GFP-positive human MSCs expressed various terminal differentiation markers, including $\alpha$-actinin, cardiac troponin $\mathrm{T}(\mathrm{cTnT})$, and connexin-43 (Cn43), as shown in Figure 5 (left and middle columns). On the other hand, some cell lines did not differentiate into beating cardiomyocytes under identical 
conditions. For example, UE7T-9 cell lines hardly showed periodical contractions and rarely expressed the terminal markers of cardiomyocytes (Figure 5, right column).

\section{$\mathrm{V}$-1.2. Expression analysis of $\mathbf{N}$-cadherin in MSCs}

The expression of various cell surface proteins, which are essential for the development of the heart in vivo or which are specifically expressed in cardiovascular progenitor cells, was examined by immunoblotting (Figure 6). Among these markers, the expression of $\mathrm{N}$-cadherin showed a relatively good correlation with the efficiency of differentiation toward beating cardiomyocytes. The MSC lines highly expressing $\mathrm{N}$-cadherin showed a higher capacity for differentiation toward cardiomyocytes. In contrast, MSCs that did not readily differentiate into cardiomyocytes expressed low levels of N-cadherin. Flk1 has been suggested to be a prospective cell surface marker of cardiomyocyte progenitor cells (Kattman et al., 2006; Yamashita et al., 2005). In our experiments, Flk1 showed an expression pattern similar to that of $\mathrm{N}$-cadherin. However, the expression levels of Flk1 in human MSCs were extremely low. We could not detect Flk1 expression after a short exposure time $(1 \mathrm{~min})$ of the immunoblotted membrane after the enhanced chemiluminescence (ECL) reaction. Only an extremely long exposure (30 min) enabled us to detect the Flk1 protein bands in human MSCs (Figure 
6). The transmembrane tyrosine kinase receptor for stem-cell factor, c-kit, has also been reported to be a cell surface marker of the cardiomyogenic progenitor cells in the neonatal heart (Tallini et al., 2009). The expression of c-kit showed some correlation with the cardiomyogenic differentiation abilities of these cells, although the expression levels of c-kit in some human MSCs that readily differentiated into cardiomyocytes were very low (Figure 3, UE7T-13, UE6E7T-11, and UBE6T-15).

Other cell surface proteins have been reported as essential for heart development. Integrin $\alpha 4$ is an essential gene for the development of the heart and placenta (Yang et al., 1995); a homozygous null mutant of integrin $\alpha 4$ caused embryonic lethality due to defects in the epicardium and coronary vessel development, leading to cardiac hemorrhage, in addition to failure of fusion between the allantois and chorion during placentation. Knockout mice of another cell adhesion molecule, vascular cell adhesion molecule 1 (VCAM-1), displayed a reduction in the compact layer of the ventricular myocardium and intraventricular septum (Kwee et al., 1995). Pdgfra is expressed in cardiac progenitor cells in the posterior part of the secondary heart field. Pdgfr $\alpha$ is also expressed in the valves and pericardia of the heart at E12.5-16.5 (Takamura et al., 1997). However, the expression of these cell surface proteins did not show a strong correlation with the differentiation ability of human MSCs into 
cardiomyocytes (Figure 4 and 6).

Next, we further verified the cell surface-specific expression of three candidate proteins, namely, N-cadherin, Flk1, and c-kit, in living MSCs by flow cytometry. The expression of Flk1 was again barely detectable on the cell surface of human MSCs (Figure 7B). In contrast, HUVEC (positive control cells) showed strong cell surface expression of Flk1 (Figure 7B, right), indicating that human MSCs do not express detectable amounts of Flk1 on the plasma membrane. The cell surface expression of c-kit was also relatively low (Figure 7C), and the MSC lines with higher differentiation ability toward cardiomyocytes did not show a significant amount of cell surface expression of c-kit (Figure 7C, UE7T-13). In contrast, the expression of N-cadherin was readily detectable in the human MSC lines with high differentiation ability toward beating cardiomyocytes (Figure 7A). When the cell surface expression of $\mathrm{N}$-cadherin (Figure 8) and the ability of human MSC cell lines to differentiate into beating cardiomyocytes (Figure 4) were carefully compared with human MSC cell lines, a strong correlation was observed between these two events $(r=0.81$; Figure 9$)$. These results suggest that $\mathrm{N}$-cadherin could be a good prospective cell surface marker of cardiomyogenic human MSCs. 


\section{V -1.3.Efficiency of differentiation of primary MSCs into beating cardiomyocytes and correlation with the expression of $\mathbf{N}$-cadherin}

Next, we validated the expression of $\mathrm{N}$-cadherin by using various type of primary human MSCs, including MSCs derived from bone marrow and adipose tissues, as described in Figure 10 - 15. Human bone marrow-derived MSCs (BMSCs) cultured for a limited number of passages showed different cell surface expression levels of $\mathrm{N}$-cadherin and differentiation abilities to cardiomyocytes, when mouse embryonic cardiomyocyte feeder cells were analyzed by the above-mentioned co-culture methods. However, a good correlation was observed between the cell surface expression of $\mathrm{N}$-cadherin and the ability to differentiate into beating cardiomyocytes (Figure 10 and 11). Human MSCs derived from adipose tissue (ASCs) also showed results similar to those obtained with the BMSCs (Figure 13 and 14). The Pearson's correlation coefficients of cell surface expression of $\mathrm{N}$-cadherin and efficiency of differentiation into beating cardiomyocytes in BMSCs and ASCs were good in both cases (0.55 and 0.77, respectively; FIG. 11 and 14). Primary ASCs (Sterneckert et al., 2012) did not differentiate into beating cardiomyocytes despite the significant expression of N-cadherin. However, the growth of ASCs (Sterneckert et al., 2012) was relatively slow and the morphology of the cells were large and flattened compared to other primary 
ASCs, which suggests unknown deficits of this batch of ASCs. Based on the results obtained from primary MSCs, we further confirmed that N-cadherin was a reliable cell surface marker for predicting the cardiomyogenic ability of human MSCs obtained from bone marrow and adipose tissue.

\section{V -2 Magnetic cell sorting based of $\mathrm{N}$-cadherin expression}

\section{V -2.1. Demonstration of magnetic cell sorting}

To determine whether the N-cadherin-positive population of human MSCs had a greater ability to differentiate into cardiomyocytes than N-cadherin-negative MSCs, we first optimized the separation conditions of $\mathrm{N}$-cadherin-positive cells using magnetic cell sorting (MACS). The N-cadherin-positive and highly cardiomyogenic MSC line, EPC-214 (Figure 17A), was infected with a GFP-expressing lentivirus and mixed with the DDEO-SE-labeled N-cadherin-negative human leukemia cell line, TF-1 (Figure 17B), to yield a mixed population containing about $20 \% \mathrm{~N}$-cadherin-positive cells (Figure 17C). After purification with anti-N-cadherin antibody-conjugated beads, the concentration of N-cadherin-positive EPC-214 cells increased to 91\% (Figure 17E), demonstrating that our conditions for MACS purification were efficient enough to concentrate N-cadherin-positive human MSCs from a mixture. 


\section{V -2.2. Magnetic cell sorting of hMSCs and their differentiation ability}

Next, the $\mathrm{N}$-cadherin-positive fraction was concentrated from a primary culture of human ASCs (1212 used in Figure 13-15) using the same method (Figure 18 and Figure 18); these cells were further cultured on mouse embryonic heart feeder cells for 7 days. As shown in Figure 20, the enriched ASC fraction expressing cell surface N-cadherin showed a 4-fold higher cardiomyogenic differentiation capacity than that of the $\mathrm{N}$-cadherin-negative fraction.

\section{V -2.3. Characterization of $\mathrm{N}$-cadherin positive cells}

To characterize the cardiomyogenic $\mathrm{N}$-cadherin-positive population, we analyzed the gene expression profiles of the MACS-sorted fractions obtained from human MSCs by using an Agilent Whole Human Genome array. When the expression of various lineage marker genes was compared, the N-cadherin-positive fraction showed up-regulated expression of genes involved in the differentiation of cardiomyocytes and skeletal myocytes, such as Nkx2.5, Handl, Tnni3 (cTnI), and Myog (Figure 21). In contrast, other lineage markers, including those of ectodermal and endodermal lineages, were the same among the MACS-sorted fractions, with the exception of Pax4, a transcription factor involved in pancreatic development, which showed higher expression in 
N-cadherin-positive cells. Although MSCs differentiate into osteoblasts, chondrocytes, and adipocytes at higher efficiency, the specific markers of these lineages did not show a large marked difference between the $\mathrm{N}$-cadherin-positive and $\mathrm{N}$-cadherin-negative fractions. The expression of MSC-specific cell surface markers was also not increased in the $\mathrm{N}$-cadherin-positive fraction.

Next, elevated expression of the cardiomyogenic lineage markers in the $\mathrm{N}$-cadherin-positive population was validated by qPCR. A cardiomyogenic precursor-specific gene, $N k x 2.5$, was expressed in the N-cadherin-positive fraction, at levels 200-times higher than that in the $\mathrm{N}$-cadherin-negative fraction. Two other transcription factors, Handl and Gata4, which are involved in cardiomyogenesis, also showed significantly elevated expression in the N-cadherin-positive fraction (Figure 22). However, the expression of other cardiomyogenic transcription factors such as $T b x 5$ was not elevated in N-cadherin-positive cells. Interestingly, the expression of Myog, a transcription factor involved in skeletal muscle development, was also elevated in the $\mathrm{N}$-cadherin-positive fraction. Although some terminal markers for cardiomyocytes, such as $A N P$ and $c T n I$, showed higher expression in the N-cadherin-positive fraction (Figure 23), the expression levels of these terminal markers were very low, suggesting that $\mathrm{N}$-cadherin-positive cells may be ready for differentiation, but not terminally 
differentiated into cardiomyocytes.

Interestingly, the expression of some pluripotency-specific genes such as Pou5f1 (Oct4), Sall4, and Nanog was significantly up-regulated in the $\mathrm{N}$-cadherin-positive population (Figure 24). These data were confirmed by qPCR (Figure 25). Recent studies have suggested that there are at least 2 splice variants of the Oct4 gene: Oct4A and Oct4B. Oct4A is highly expressed in ES/iPS cells and regulates the pluripotency properties of ES cells, whereas $O c t 4 B$, which lacks exon1 but contains exon 2a, does not maintain self-renewal in ES cells (Wang et al., 2010). In our experiments, N-cadherin-positive cells expressed significantly elevated levels of both Oct4A and Oct4B compared to the expression in N-cadherin-negative cells (Figure 25). The expression level of Oct4 and Nanog mRNAs in human MSCs was not as high as those in human ES cells (Figure 25), suggesting that these genes up-regulated in N-cadherin-positive MSCs may not exhibit the pluripotency as observed in ES/iPS cells. However, recent reports have suggested that the expression of Oct4 in MSCs is correlates with the multiple differentiation abilities of MSCs. For example, overexpression of Oct4 enhanced the differentiation ability of MSCs (Liu et al., 2009), and knockdown of Oct4 caused loss of multiple differentiation potential (Tsai et al., 2012). Nanog was also shown to possess similar activity in BMSCs (Go et al., 2008). 
Therefore, our data suggest that N-cadherin-positive cells with up-regulated expression of Oct4 and other transcription factors responsible for cardiomyogenesis could increase the ability of MSCs for differentiation into cardiomyocytes. 


\section{Discussion}

Among various cell surface markers reported to be essential for heart development or to be specific for their expression in cardiovascular tissues, results of immunoblotting analysis of various MSC lines identified three candidate markers (N-cadherin, Flk1, and c-kit) as prospective cell surface markers of MSCs that have a higher cardiomyogenic differentiation capacity. These markers showed some correlation between their expression and the efficiency of differentiation of these MSCs into beating cardiomyocytes.

Although Flk1 has been reported to be a cell surface marker for the multipotent cardiovascular progenitors observed during the differentiation of human and mouse ES cells (Kattman et al., 2006; Yamashita et al., 2005, Yang L et al., 2008). However, the cell surface expression level of Flk1 was quite low in human MSCs as analyzed by flow cytometry (Figure 7B). Therefore, our results suggest that it is not practical to use Flk1 as a cell surface marker for human MSCs that have a strong ability to differentiate into cardiomyocytes.

Our immunoblotting analysis also suggested c-kit as a prospective cell surface marker for cardiomyogenic human MSCs. Although we observed expression of c-kit in the EPC-214 cell line that efficiently differentiated into beating cardiomyocytes in vitro, 
the cell surface expression of c-kit was not detectable by flow cytometry in the other MSC line that readily differentiated into cardiomyocytes (Figure 7C, UE7T-13). These results suggested that c-kit is also not a reliable prospective cell surface marker for human MSCs with high cardiomyogenic ability.

In contrast to Flk1 and c-kit, the expression of N-cadherin was much higher, and could be reproducibly detected by flow cytometry in MSCs with high cardiomyocyte differentiation ability (Figure 4, 7A, 8, 9). There was also a good correlation between the $\mathrm{N}$-cadherin expression and cardiomyogenic potential of primary human BMSCs and ASCs (Figure 9-14), further indicating that N-cadherin is a good prospective cell surface marker for human MSCs having high cardiomyogenic potential. In addition, the expression of $\mathrm{N}$-cadherin continues from cardiomyogenic progenitor cells to mature cardiomyocytes in the adult heart. $\mathrm{N}$-cadherin maintains the functional gap junction complex at the plasma membrane in the adult heart, and conditional knockout of N-cadherin in mice resulted in cardiac arrhythmia in adults, with significant decreases in $\mathrm{Cx} 43$ and $\mathrm{Cx} 40$ levels ( $\mathrm{Li}$ et al, 2005). Based on these observations, $\mathrm{N}$-cadherin seems to be a useful and reliable cell surface marker for human MSCs with increased capacity for differentiation toward cardiomyocytes. In contrast, cardiac differentiated cells from N-cadherin-overexpressing mouse ES cells show good 
adhesion to cultured cardiomyocytes, (Karabekian et al, 2009).

We have previously shown that cardiomyogenic progenitor cells differentiated from mouse ES cells express high levels of N-cadherin on the surface of the cell membrane, and that an antibody against $\mathrm{N}$-cadherin could be used to concentrate the progenitor cells from a heterogeneous cell population differentiated from mouse ES cells (Honda et al., 2006). Although the possible pathway of differentiation of cardiomyocytes from pluripotent ES cells and multipotent MSCs may not be the same, $\mathrm{N}$-cadherin could be a common progenitor marker of the cardiomyogenic cells derived from these stem cells.

Purification of N-cadherin-positive cells from primary human MSCs cells with anti-N-cadherin-conjugated magnetic beads made it possible to concentrate human MSCs with greater ability to differentiate toward cardiomyocytes. Interestingly, the purified N-cadherin-positive fraction showed significantly higher expression of several cardiomyogenic progenitor cell-specific transcription factors such as $N k x 2.5$, Handl, and Gata4. Although the overall absolute expression level of cardiomyocyte-specific terminal markers was low, some of the cardiomyocyte-specific marker levels were higher in the N-cadherin-positive fractions. These results suggest a possible reason for the higher potential of N-cadherin-positive MSCs for differentiating into 
cardiomyocytes.

In addition to cardiomyogenic genes, we observed increased expression of pluripotency-specific transcription factors of ES cells, such as Oct, Sall4, and Nanog, in the N-cadherin-positive fraction. Recently, Oct4 was suggested to not simply be a reprogramming factor for generating iPS cells nor transcription factor specific for ES cells and genital organ, but rather to be the gatekeeper into and out of the reprogramming expressway that can be directed by altering experimental conditions (Sterneckert et al, 2012). Therefore, the elevated expression of Oct4 and related transcription factors could positively modulate the differentiation ability of MSCs.

Although this study revealed that $\mathrm{N}$-cadherin is a cell surface marker for human MSCs that have a strong ability to differentiate into cardiomyocytes, the efficiency of differentiation should be improved and the transplant technique should be explored for clinical application. Previously some regulatory pathways of cardiomyocyte differentiation have shown that $\mathrm{Wnt} / \beta$-catenin signaling is an important regulator of cardiomyocyte differentiation from human ES cells via induction with activin A and BMP4 (Paige et al., 2010). Shimoji et al. (2010) screened for humoral factors that promote cardiomyocyte differentiation from ES cells, and found that G-CSF is significantly involved in cardiomyocyte proliferation. These finding indicate the 
possibility that the efficiency of differentiation cells into cardiomyocytes will be increased by these factors. During the administration of differentiated cardiomyocytes, aggregate formation of pluripotent sten cell-derived cardiomyocytes improved their survival in the immunodeficient mouse heart because of homophilic cell-cell adhesion (Hattori et al., 2010). Recently, cell sheet-based tissue engineering has yielded satisfactory therapeutic results in cardiac disease (Haraguchi et al., 2011). The use of a cardiogenic cell surface marker, such as N-cadherin, in these methods would facilitate their clinical application. 


\section{Acknowledgements}

First of all, I wish to express my special gratitude to Associate Prof. Akira Kurisaki who, with his constructive criticism, enabled me to successfully finish this dissertation.

I am grateful to all the members of National Institute of Advanced Industrial Science and Technology, Research Center for Stem Cell Engineering for valuable discussions.

I would also like to thank Prof. Jun-Ichi Hayashi, Prof. Kazuto Nakada, and Prof.

Pi-Chao Wang, Graduate School of Life and Environment Sciences, University of Tsukuba for their in valuable advice. 


\section{References}

Bolli, R., Chugh, A.R., D’Amario, D., Loughran, J.H., Stoddard, M.F., Ikram, S., Beache, G.M., Wagner, S.G., Leri, A., Hosoda, T., et al. Cardiac stem cells in patients with ischaemic cardiomyopathy (SCIPIO): initial results of a randomised phase 1 trial. Lancet 378, 1847-1857. 2011.

Cai CL, Liang X, Shi Y, Chu PH, Pfaff SL, Chen J, Evans S. Isl1 identifies a cardiac progenitor population that proliferates prior to differentiation and contributes a majority of cells to the heart. Dev Cell.5:877-89. 2003

Caplan AI, Correa D. The MSC: an injury drugstore. Cell Stem Cell.9:11-5. 2011.

Chen SL, Fang WW, Ye F, Liu YH, Qian J, Shan SJ, Zhang JJ, Chunhua RZ, Liao LM, Lin S, Sun JP. Effect on left ventricular function of intracoronary transplantation of autologous bone marrow mesenchymal stem cell in patients with acute myocardial infarction. Am J Cardiol.94:92-5. 2004. 
Ema M, Takahashi S, Rossant J. Deletion of the selection cassette, but not cis-acting elements, in targeted Flk1-lacZ allele reveals Flk1 expression in multipotent mesodermal progenitors. Blood.107:111-7. 2006.

Ferrari SL, Traianedes K, Thorne M, Lafage-Proust MH, Genever P, Cecchini MG, Behar V, Bisello A, Chorev M, Rosenblatt M, Suva LJ. A role for N-cadherin in the development of the differentiated osteoblastic phenotype. J Bone Miner Res. 15(2):198-208. 2000.

Go MJ, Takenaka C, Ohgushi H. Forced expression of Sox 2 or Nanog in human bone marrow derived mesenchymal stem cells maintains their expansion and differentiation capabilities. Exp Cell Res.314:1147-54. 2008.

Haraguchi Y, Shimizu T, Yamato M, Okano T. Regenerative Therapies Using Cell Sheet-Based Tissue Engineering for Cardiac Disease. Cardiology Research and Practice Volume 2011, Article ID 845170, 8 pages. 2011.

Hatta K, Takeichi M. Expression of N-cadherin adhesion molecules associated with 
early morphogenetic events in chick development. Nature.320:447-449. 1986

Hattori F, Chen H, Yamashita H, Tohyama S, Satoh YS, Yuasa S, Li W, Yamakawa H, Tanaka T, Onitsuka T, Shimoji K, Ohno Y, Egashira T, Kaneda R, Murata M, Hidaka K, Morisaki T, Sasaki E, Suzuki T, Sano M, Makino S, Oikawa S, Fukuda K. Nongenetic method for purifying stem cell-derived cardiomyocytes. Nat Methods. 7(1):61-6. 2010.

Honda M, Kurisaki A, Ohnuma K, Okochi H, Hamazaki TS, Asashima M. N-cadherin is a useful marker for the progenitor of cardiomyocytes differentiated from mouse ES cells in serum-free condition. Biochem Biophys Res Commun.351:877-82. 2006.

Iijima Y, Nagai T, Mizukami M, Matsuura K, Ogura T, Wada H, Toko H, Akazawa H, Takano H, Nakaya H, Komuro I. Beating is necessary for transdifferentiation of skeletal muscle-derived cells into cardiomyocytes. FASEB J. 17(10):1361-3. 2003.

Kajstura J, Rota M, Whang B, Cascapera S, Hosoda T, Bearzi C, Nurzynska D, Kasahara H, Zias E, Bonafé M, Nadal-Ginard B, Torella D, Nascimbene A, Quaini F, Urbanek K, Leri A, Anversa P. Bone Marrow Cells Differentiate in Cardiac Cell 
Lineages After Infarction Independently of Cell Fusion. Circ Res. 96(1):127-37. (2005)

Kamada M, Kumazaki T, Matsuo T, Mitsui Y, Takahashi T. Establishment of ultra long-lived cell lines by transfection of TERT into normal human fibroblast TIG-1 and their characterization. Cell Biol Int.36:519-27. 2012.

Karabekian Z, Gillum ND, Wong EW, Sarvazyan N. Effects of N-cadherin overexpression on the adhesion properties of embryonic stem cells. Cell Adh Migr. 3(3):305-10. 2009

Kattman SJ, Huber TL, Keller GM. Multipotent flk-1+ cardiovascular progenitor cells give rise to the cardiomyocyte, endothelial, and vascular smooth muscle lineages. Dev Cell.11:723-32. 2006.

Kwee L, Baldwin HS, Shen HM, Stewart CL, Buck C, Buck CA, Labow MA. Defective development of the embryonic and extraembryonic circulatory systems in vascular cell adhesion molecule (VCAM-1) deficient mice. Development.121:489-503. 1995. 
Kyo S, Nakamura M, Kiyono T, Maida Y, Kanaya T, Tanaka M, Yatabe N, Inoue M. Successful immortalization of endometrial glandular cells with normal structural and functional characteristics. Am J Pathol.163:2259-69. 2003.

Laflamme MA, Chen KY, Naumova AV, Muskheli V, Fugate JA, Dupras SK, Reinecke H, Xu C, Hassanipour M, Police S, O'Sullivan C, Collins L, Chen Y, Minami E, Gill EA, Ueno S, Yuan C, Gold J, Murry CE. Cardiomyocytes derived from human embryonic stem cells in pro-survival factors enhance function of infarcted rat hearts. Nat Biotechnol. (9):1015-24.2007

Laugwitz KL, Moretti A, Lam J, Gruber P, Chen Y, Woodard S, Lin LZ, Cai CL, Lu MM, Reth M, Platoshyn O, Yuan JX, Evans S, Chien KR. Postnatal isl1+ cardioblasts enter fully differentiated cardiomyocyte lineages. Nature.433:647-53. 2005.

Leobon, B., Garcin, I., Menasche, P., Vilquin, J.T., Audinat, E., and Charpak, S. Myoblasts transplanted into rat infarcted myocardium are functionally isolated from their host. Proc. Natl. Acad. Sci. 100, 7808-7811. 2003. 
Li J, Patel VV, Kostetskii I, Xiong Y, Chu AF, Jacobson JT, Yu C, Morley GE, Molkentin JD, Radice GL. Cardiac-specific loss of N-cadherin leads to alteration in connexins with conduction slowing and arrhythmogenesis. Circ Res.97:474-81. 2005.

Li M, Naqvi N, Yahiro E, Liu K, Powell PC, Bradley WE, Martin D.I.K., Graham R.M., Dell'Italia L.J., and Husain A. c-kit is required for cardiomyocyte terminal differentiation. Circ Res.102:677-85. 2008.

Lints TJ, Parsons LM, Hartley L, Lyons I, Harvey RP. Nkx-2.5: a novel murine homeobox gene expressed in early heart progenitor cells and their myogenic descendants. Development.119:419-31. 1993.

Liu TM, Wu YN, Guo XM, Hui JH, Lee EH, Lim B. Effects of ectopic Nanog and Oct4 overexpression on mesenchymal stem cells. Stem Cells Dev.18:1013-22. 2009.

Maeda T, Tashiro H, Katabuchi H, Begum M, Ohtake H, Kiyono T, Okamura H. Establishment of an immortalised human ovarian surface epithelial cell line without chromosomal instability. Br J Cancer.93:116-23. 2005. 
Makino S, Fukuda K, Miyoshi S, Konishi F, Kodama H, Pan J, Sano M, Takahashi T, Hori S, Abe H, Hata J, Umezawa A, Ogawa S. Cardiomyocytes can be generated from marrow stromal cells in vitro. J Clin Invest.103:697-705. 1999.

Moretti A, Caron L, Nakano A, Lam JT, Bernshausen A, Chen Y, Qyang Y, Bu L, Sasaki M, Martin-Puig S, Sun Y, Evans SM, Laugwitz KL, Chien KR. Multipotent embryonic isl1+ progenitor cells lead to cardiac, smooth muscle, and endothelial cell diversification. Cell.127:1151-65. 2006.

Mori T, Kiyono T, Imabayashi H, Takeda Y, Tsuchiya K, Miyoshi S, Makino H, Matsumoto K, Saito H, Ogawa S, Sakamoto M, Hata J, Umezawa A. Combination of TERT and bmi-1, E6, or E7 induces prolongation of the life span of bone marrow stromal cells from an elderly donor without affecting their neurogenic potential. Mol Cell Biol.25:5183-95. 2005.

Nygren JM, Jovinge S, Breitbach M, Sawen P, Roll W, Hescheler J, Taneera J, Fleischmann BK, Jacobsen SE. Bone marrow-derived hematopoietic cells generate cardiomyocytes at a low frequency through cell fusion, but not transdifferentiation. Nat 
Med.10:494-501. 2004.

Omi H, Okamoto A, Nikaido T, Urashima M, Kawaguchi R, Umehara N, Sugiura K,

Saito M, Kiyono T, Tanaka T. Establishment of an immortalized human extravillous trophoblast cell line by retroviral infection of E6/E7/TERT and its transcriptional profile during hypoxia and reoxygenation. Int J Mol Med.23:229-36. 2009.

Paige SL, Osugi T, Afanasiev OK, Pabon L, Reinecke H, Murry CE. Endogenous Wnt/ß-Catenin Signaling Is Required for Cardiac Differentiation in Human Embryonic Stem Cells. PLoS ONE 5(6): e11134. 2010

Puch S., Armeanu S., Kibler C., Johnson KR., Müller CA., Wheelock MJ., Klein G. $\mathrm{N}$-cadherin is developmentally regulated and functionally involved in early hematopoietic cell differentiation. J. Cell Sci. 114:1567-1577. 2001

Radice GL, Rayburn H, Matsunami H, Knudsen KA, Takeichi M, Hynes RO. Developmental defects in mouse embryos lacking N-cadherin. Dev Biol.181:64-78. 1997. 
Shimoji K, Yuasa S, Onizuka T, Hattori F, Tanaka T, Hara M, Ohno Y, Chen H, Egasgira T, Seki T, Yae K, Koshimizu U, Ogawa S, Fukuda K. G-CSF promotes the proliferation of developing cardiomyocytes in vivo and in derivation from ESCs and iPSCs. Cell Stem Cell. 6(3): 227-37. (2010)

Shiota M, Heike T, Haruyama M, Baba S, Tsuchiya A, Fujino H, Kobayashi H, Kato T, Umeda K, Yoshimoto M, Nakahata T. Isolation and characterization of bone marrow-derived mesenchymal progenitor cells with myogenic and neuronal properties. Exp Cell Res.313:1008-23. 2007.

Sterneckert J, Hoing S, Scholer HR. Concise review: Oct4 and more: the reprogramming expressway. Stem Cells.30:15-21. 2012.

Takahashi, K., Tanabe, K., Ohnuki, M., Narita, M., Ichisaka, T., Tomoda, K., and Yamanaka, S. Induction of pluripotent stem cells from adult human fibroblasts by defined factors. Cell 131, 861-872. 2007. 
Takakura N, Yoshida H, Ogura Y, Kataoka H, Nishikawa S. PDGFR alpha expression during mouse embryogenesis: immunolocalization analyzed by whole-mount immunohistostaining using the monoclonal anti-mouse PDGFR alpha antibody APA5. J Histochem Cytochem.45:883-93. 1997. Tallini YN, Greene KS, Craven M, Spealman A, Breitbach M, Smith J, Patricia J. Fisher P. J., Steffey M, Hesse M, Robert M. Doran R M, Woods A, Singh B, Yen A, Fleischmann BK, Kotlikoff MI. c-kit expression identifies cardiovascular precursors in the neonatal heart. Proc Natl Acad Sci U S A.106:1808-13. 2009.

Tesar PJ, Chenoweth JG, Brook FA, Davies TJ, Evans EP, Mack DL, Gardner RL, McKay RD. New cell lines from mouse epiblast share defining features with human embryonic stem cells. Nature.448:196-9. 2007.

Tsai CC, Su PF, Huang YF, Yew TL, Hung SC. Oct4 and Nanog directly regulate Dnmt1 to maintain self-renewal and undifferentiated state in mesenchymal stem cells. Mol Cell.47:169-82. 2012.

Tsuruga Y, Kiyono T, Matsushita M, Takahashi T, Kasai H, Matsumoto S, Todo S. 
Establishment of immortalized human hepatocytes by introduction of HPV16 E6/E7 and TERT as cell sources for liver cell-based therapy. Cell Transplant.17:1083-94. 2008.

Wakitani S, Saito T, Caplan AI. Myogenic cells derived from rat bone marrow mesenchymal stem cells exposed to 5-azacytidine. Muscle Nerve.18:1417-26. 1995.

Wang X, Dai J. Concise review: isoforms of OCT4 contribute to the confusing diversity in stem cell biology. Stem Cells.28:885-93. 2010.

Wu SM, Fujiwara Y, Cibulsky SM, Clapham DE, Lien CL, Schultheiss TM, Orkin SH. Developmental origin of a bipotential myocardial and smooth muscle cell precursor in the mammalian heart. Cell.127:1137-50. 2006

Yamashita JK, Takano M, Hiraoka-Kanie M, Shimazu C, Peishi Y, Yanagi K, Nakano A, Inoue E, Kita F, Nishikawa S. Prospective identification of cardiac progenitors by a novel single cell-based cardiomyocyte induction. FASEB J.19:1534-6. 2005

Yang JT, Rayburn H, Hynes RO. Cell adhesion events mediated by alpha 4 integrins are 
essential in placental and cardiac development. Development.121:549-60. 1995.

Yang L, Soonpaa MH, Adler ED, Roepke TK, Kattman SJ, Kennedy M, Henckaerts E,

Bonham K, Abbott GW, Linden RM. Human cardiovascular progenitor cells develop from a KDR+ embryonic-stem-cell-derived population. Nature.453:524-8. 2008.

Zhou K, Koike C, Yoshida T, Okabe M, Fathy M, Kyo S, Kiyono T, Saito S, Nikaido T. Establishment and characterization of immortalized human amniotic epithelial cells. Cell Reprogram.15:55-67. 2013. 
IX. Table 
Table Primers used for qPCR analysis.

\begin{tabular}{|c|c|c|}
\hline Transcript & \multicolumn{2}{|r|}{ Sequence } \\
\hline Nkx2.5 & $\mathrm{F}:$ & 5'-CGCCAACAACAACTTCGTGAAC-3' \\
\hline & $\mathrm{R}:$ & 5'-GAGCTGTTGAGGTGGGATC-3' \\
\hline \multirow[t]{2}{*}{ Hand1 } & $\mathrm{F}:$ & 5'-TTTGTTCTTCGAATCGTGGTG-3' \\
\hline & $\mathrm{R}:$ & 5'-AAAGTGTTTCCCTTGGAACTAA-3' \\
\hline \multirow[t]{2}{*}{ GATA4 } & $\mathrm{F}:$ & 5'-CACAAGGCTATGCGTCTCC-3' \\
\hline & $\mathrm{R}:$ & 5'-GCCTCCTTCTTTGCTATCCTC-3' \\
\hline \multirow[t]{2}{*}{ Tbx5 } & $\mathrm{F}:$ & 5'-TAGAGGACATCAGCTGCAACA-3' \\
\hline & $\mathrm{R}:$ & 5'-GGAGAAGTGCTGGTAGGGTA-3' \\
\hline \multirow[t]{2}{*}{ ANP } & $\mathrm{F}:$ & 5'-AGGGACAGACGTAGGCCAAGAG-3' \\
\hline & $\mathrm{R}:$ & 5'-TCTGGTCTGACCTAGGAGCTGG-3' \\
\hline \multirow[t]{2}{*}{$\mathrm{cTnT}$} & $\mathrm{F}:$ & 5'-GGCAGCGGAAGAGGATGCTGAA-3' \\
\hline & $\mathrm{R}:$ & 5'-GAGGCACCAAGTTGGGCATGAACGA-3' \\
\hline \multirow[t]{2}{*}{ cTnI } & $\mathrm{F}:$ & 5'-TGCAGATTGCAAAGCAAGAG-3' \\
\hline & $\mathrm{R}:$ & 5'-GGTGACTTTTGCCTCTATGTC-3' \\
\hline \multirow[t]{2}{*}{ MLC2a } & $\mathrm{F}:$ & 5'-GGGAGAAGCTCAATGGGACAG-3' \\
\hline & $\mathrm{R}:$ & 5'-CCACCTCAGCTGGAGAGAAC-3' \\
\hline \multirow[t]{2}{*}{ Myog } & $\mathrm{F}:$ & 5'-TGTAAGAGGAAGTCGGTGTC-3' \\
\hline & $\mathrm{R}:$ & 5'-CCTCATTCACCTTCTTGAGC-3' \\
\hline \multirow[t]{2}{*}{ Oct4 } & $\mathrm{F}:$ & 5'-GAGGAAGCTGACAACAATGA-3' \\
\hline & $\mathrm{R}:$ & 5'-TCACTCGGTTCTCGATACTG-3' \\
\hline \multirow[t]{2}{*}{ Oct4a } & $\mathrm{F}:$ & 5'-TGGAGAGCAACTCCGAT-3' \\
\hline & $\mathrm{R}:$ & 5'-TGCTCCAGCTTCTCCT-3' \\
\hline \multirow[t]{2}{*}{ Oct $4 b$} & $\mathrm{~F}:$ & 5'-AGAGGCACTTCTACAGACTA-3' \\
\hline & $\mathrm{R}:$ & 5'-GAACATAAACACACCAGTTATCAAT-3' \\
\hline \multirow[t]{2}{*}{ Nanog } & $\mathrm{F}:$ & 5'-AGCTGTGTGTACTCAATGATAG-3' \\
\hline & $\mathrm{R}:$ & 5'-AGGTCTTCACCTGTTTGTAG-3' \\
\hline \multirow[t]{2}{*}{ Sall4 } & $\mathrm{F}:$ & 5'-GAGAATCCCTGTGACTTTACG-3' \\
\hline & $\mathrm{R}:$ & 5'-GATGACATCATCATGGCAGATAG-3' \\
\hline \multirow[t]{2}{*}{ TBP } & $\mathrm{F}:$ & 5'-AATCTTGGTTGTAAACTTGACCTA-3' \\
\hline & $\mathrm{R}:$ & 5'-CTTGGGATTATATTCGGCGT-3' \\
\hline
\end{tabular}

F: forward primer; R: reverse primer. 
X. Figures and Legends 


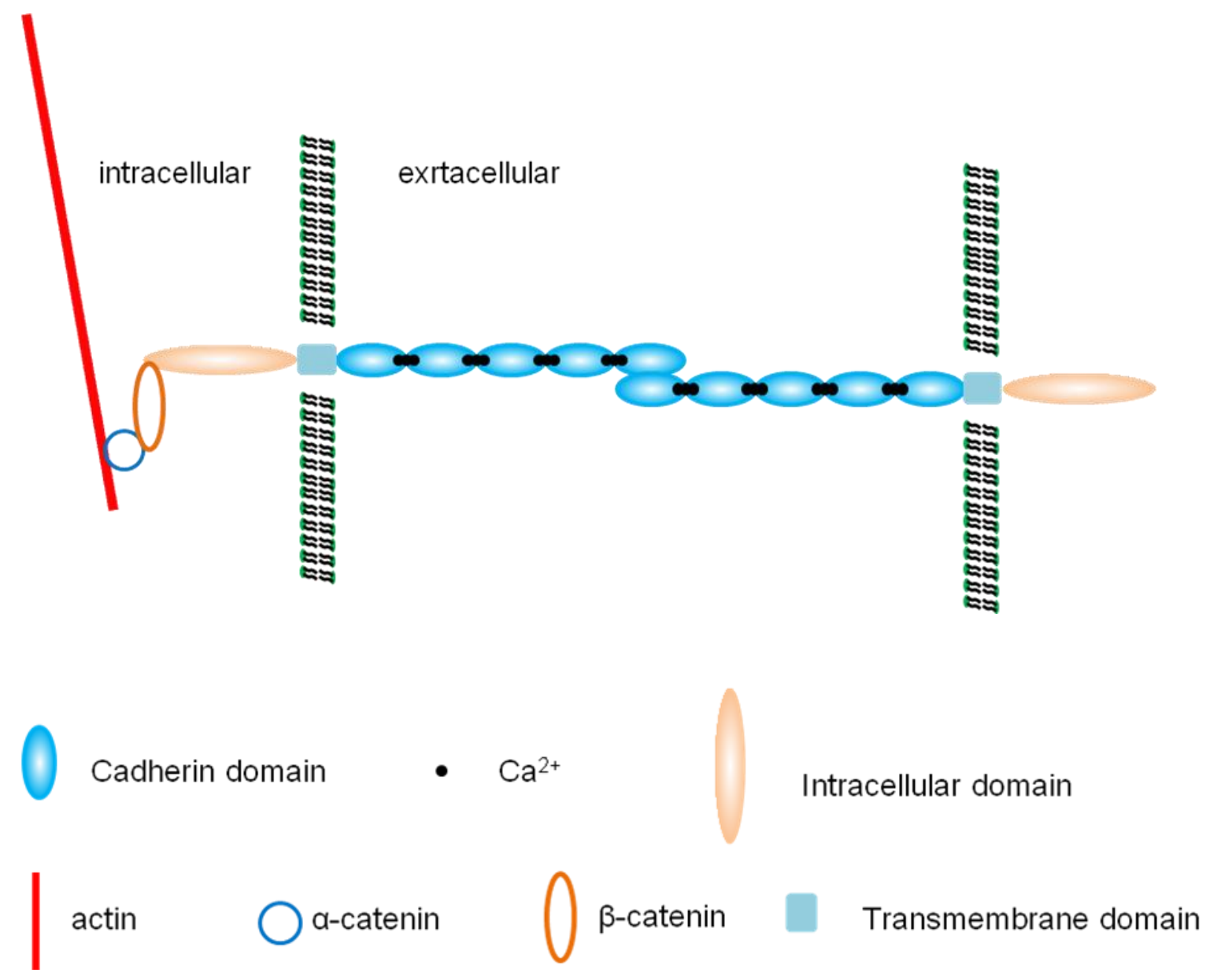

\section{Figure 1 Structure of N-cadherin.}

Schematic diagram showing the structure of the N-cadherin structure. N-cadherin is a type 1 membrane protein. $\mathrm{N}$-cadherins mediate cell-cell adhesion through homophilic interactions. $\mathrm{N}$-cadherin, have distinct expression patterns during embryonic development and in the adult. During gastrulation, N-cadherin is expressed in the primitive streak (Hatta K. et al., 1986). $\mathrm{N}$-cadherin is also involved in the development of early hematopoietic progenitor cells in the bone marrow (Puch S. et al., 2001). During later phase of osteogenic differentiation, N-cadherin is expressed in the osteoblasts and contributes to mineralization and nodule formation (Ferrari et al., 2000). 


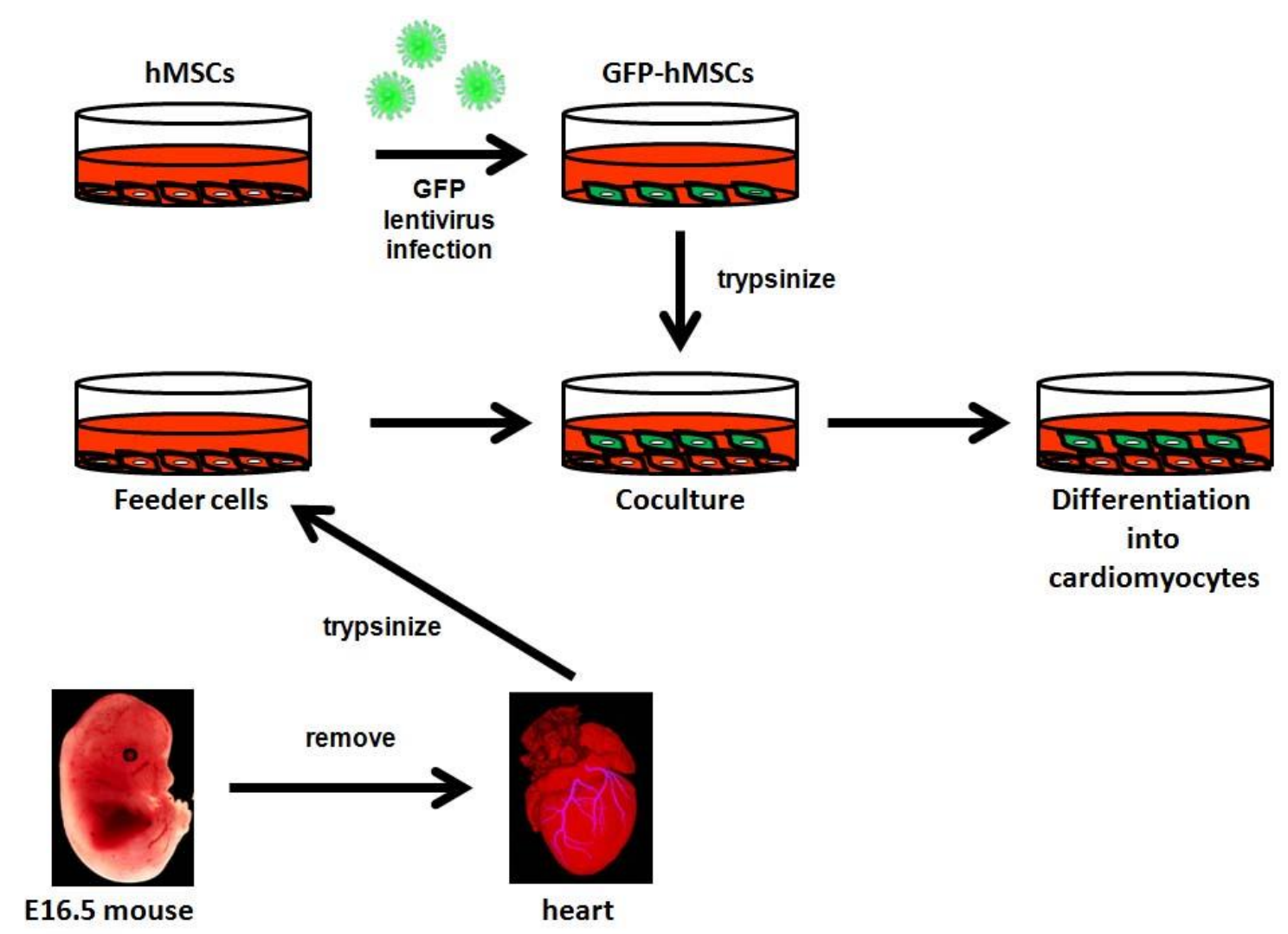

Figure 2 Schematic diagram of the co-culture method for the cardiomyocyte differentiation of human mesenchymal stem cells (hMSCs).

hMSCs were labeled by infection with GFP-expressing lentivirus, and were then co-cultured on fetal mouse cardiomyocytes for 10 days. 

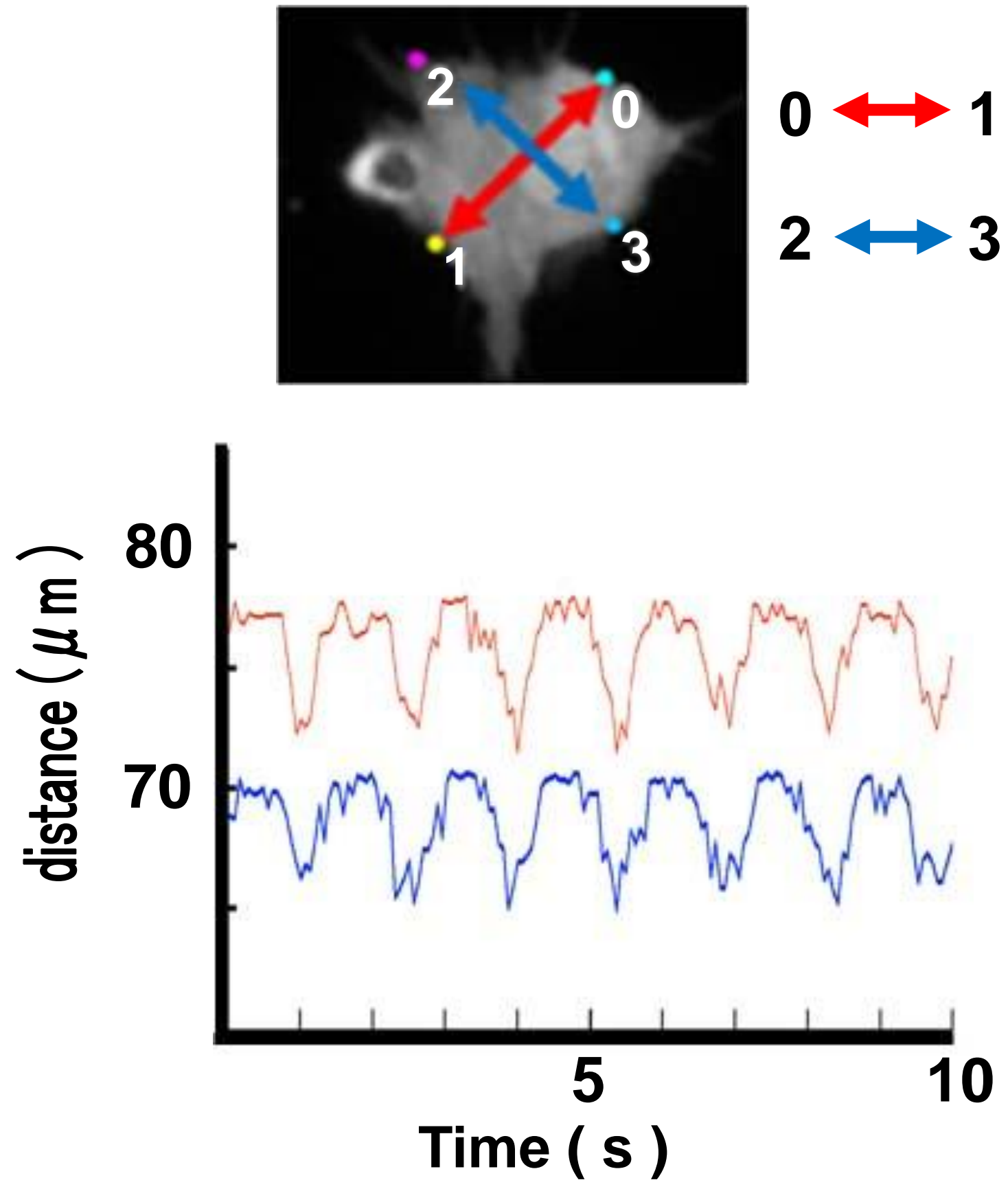

Figure 3 Periodical contractions of GFP-labeled beating cardiomyocytes derived by differentiation of human mesenchymal sten cells (MSCs) for 7 days.

Lower panel shows the time-dependent distance between points indicated in the upper panel; red line: between 0 and 1, blue line: between 2 and 3 . 


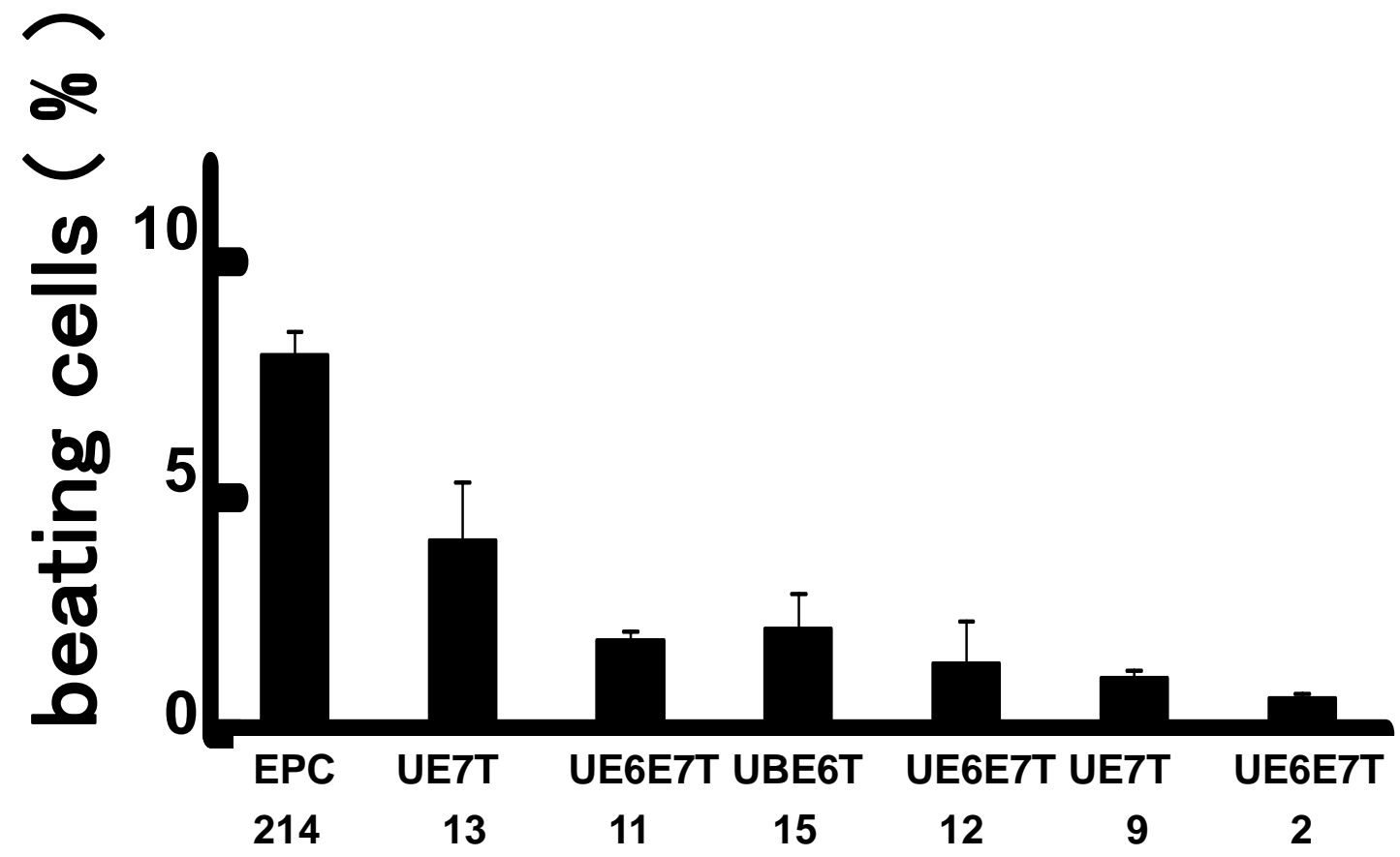

Figure 4 Autonomously beating cardiomyocytes differentiated from GFP-labeled human mesenchymal stem cell (MSC) lines were counted using a microscope.

Bar graphs represent the mean value of the differentiation efficiencies obtained from more than two independent experiments. 


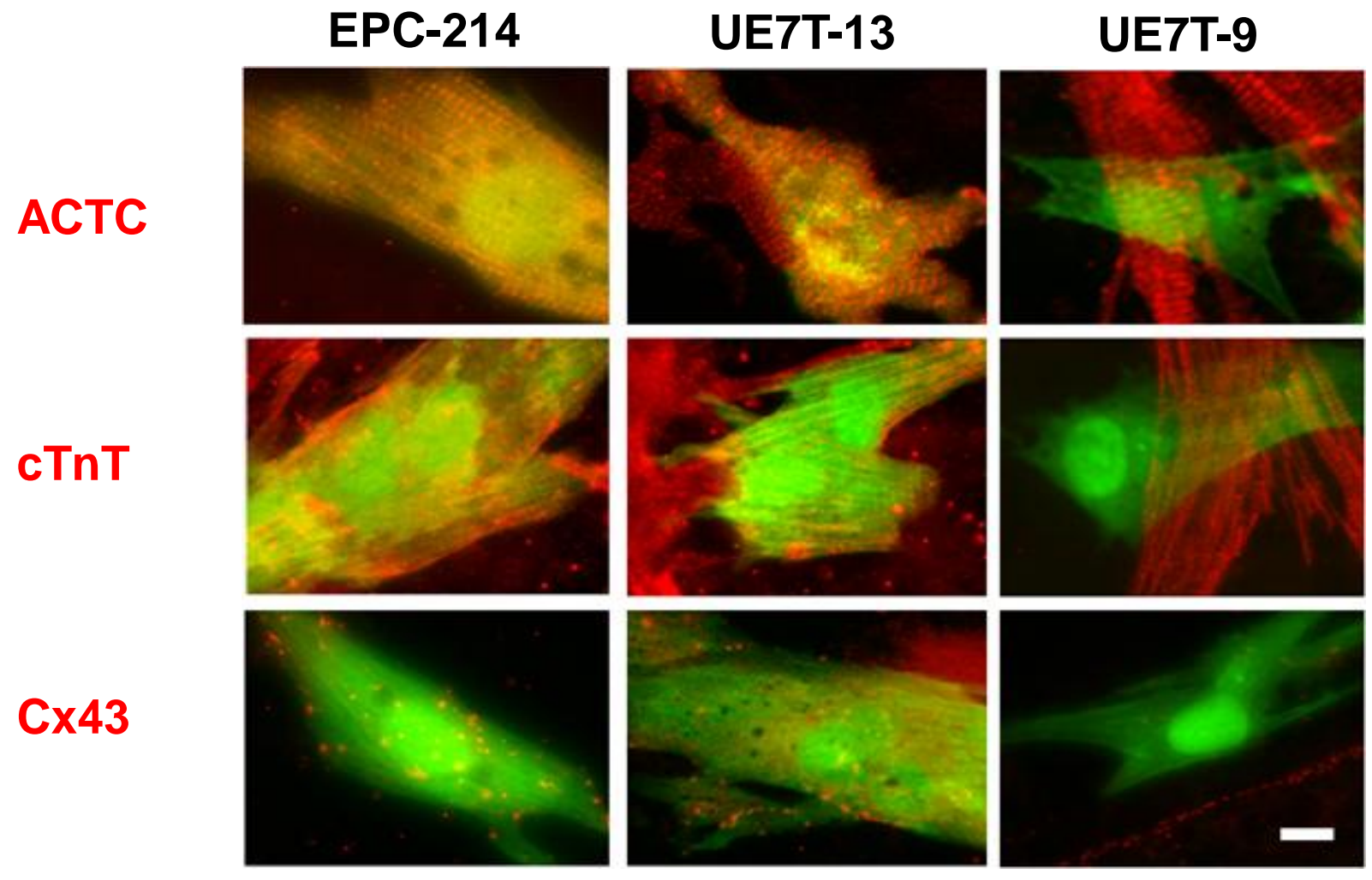

Figure 5 Expression of cardiac differentiation markers

$\alpha$-actinin (red), cTnT (red), and Cn43 (red), was analyzed by immunofluorescence staining after differentiation for 7 days. Human mesenchymal sten cells (MSCs) were labeled with GFP (green). Scale bar, $10 \mu \mathrm{m}$. 


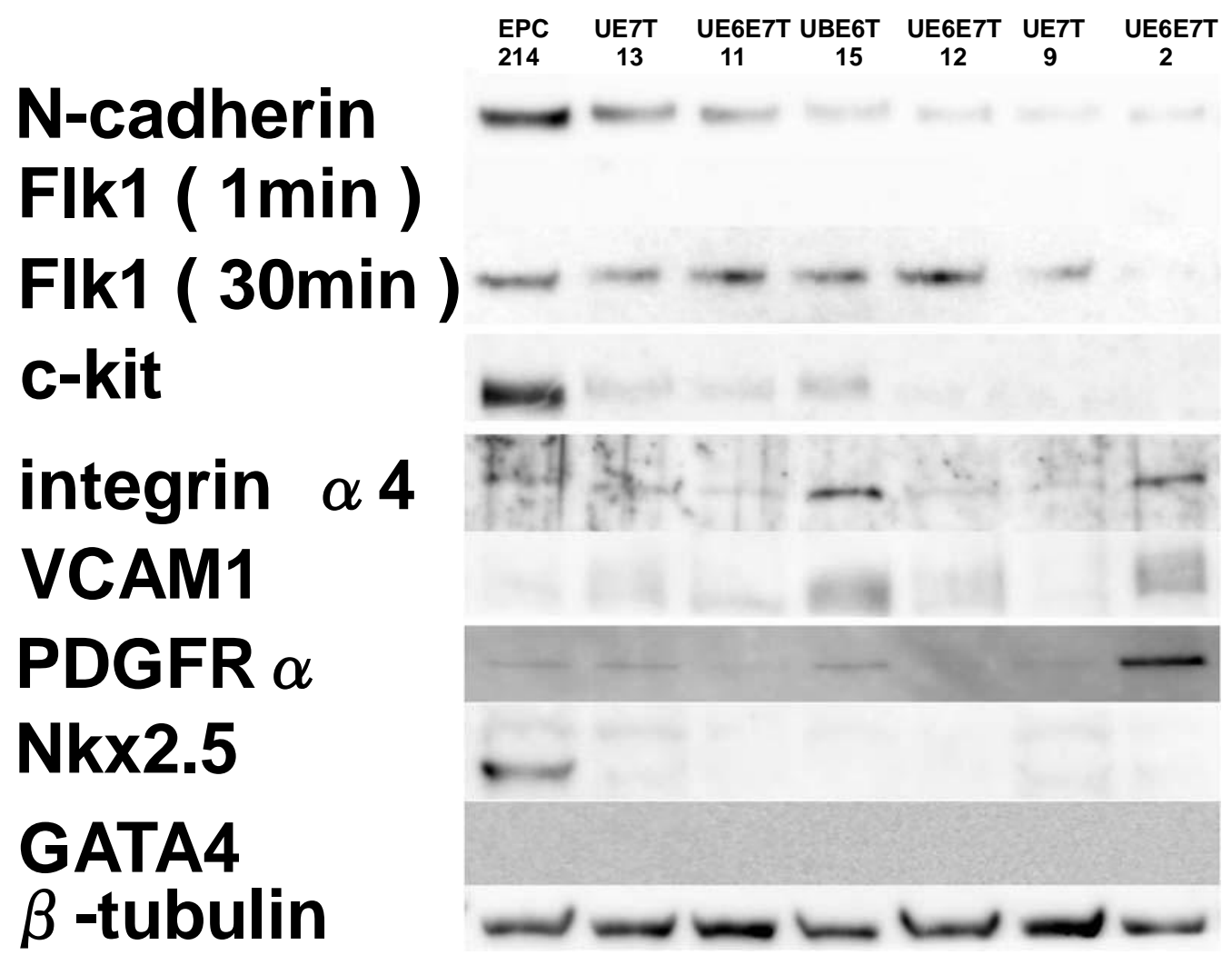

Figure 6 The expression of cell surface proteins and transcription factors related to cardiovascular development.

These data were analyzed by immunoblotting of whole cell lysates. 

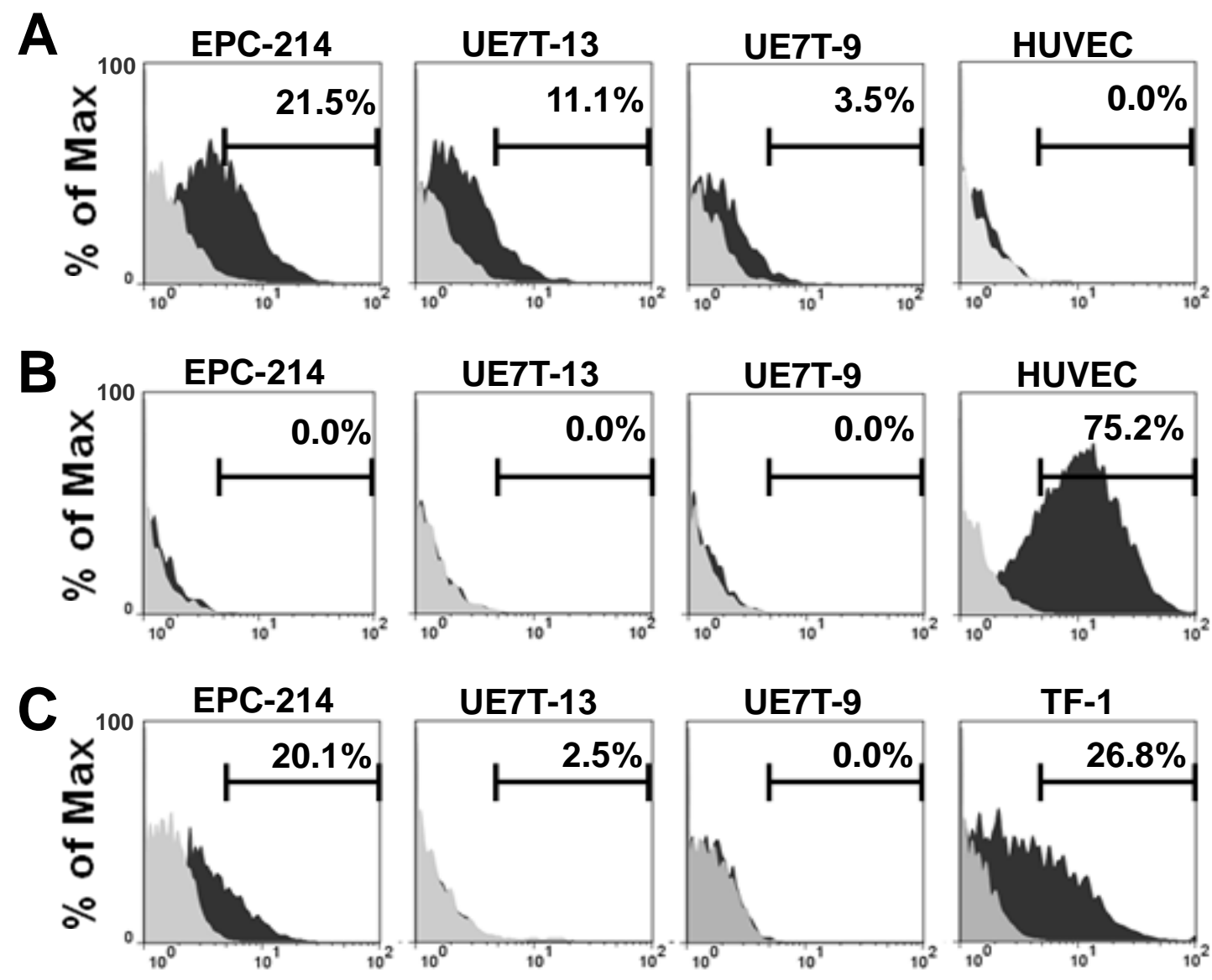

Figure 7 Representative FACS plots of cell surface $\mathbf{N}$-cadherin expression in human mesenchymal stem cell (MSC) lines.

The cells were immunostained with (A) N-cadherin, (B) Flk1, or (C) c-kit antibodies. Propidium iodide-positive cells were excluded from the analysis. 


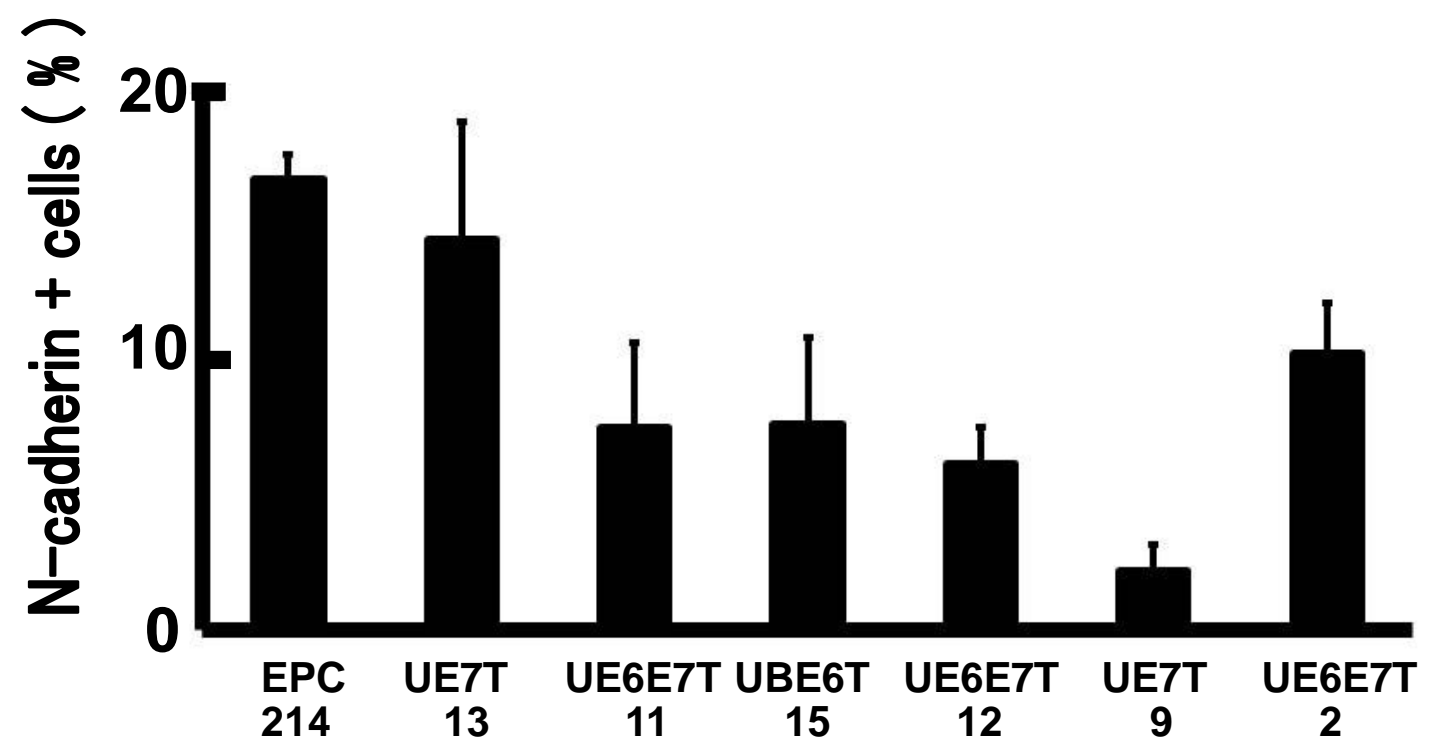

Figure 8 Flow cytometric analysis of cell surface expression of $\mathbf{N}$-cadherin in human mesenchymal stem cell (MSC) lines.

The bar graphs represent the mean value of cell surface protein expression obtained from more than two independent experiments. 


\section{$r=0.81$}

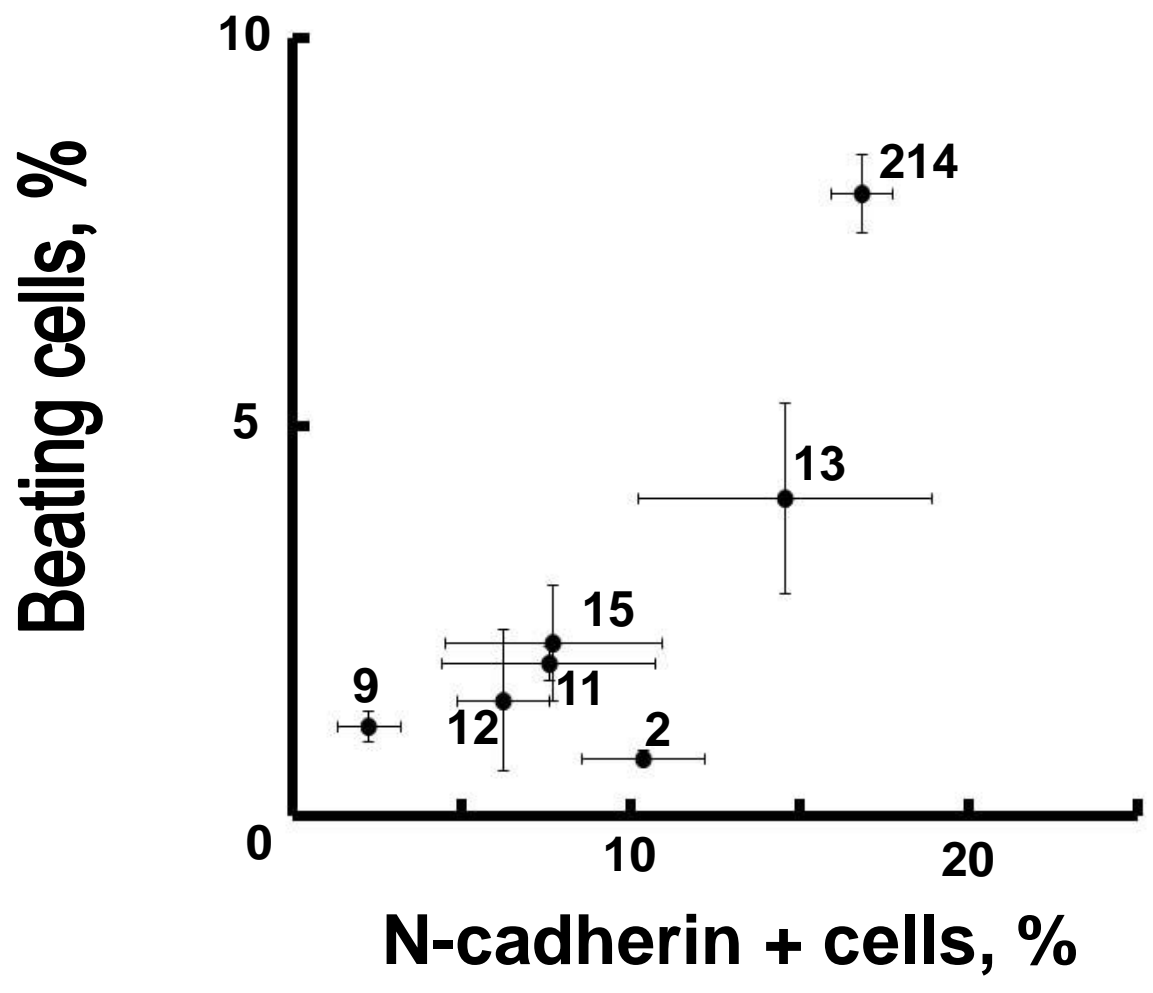

Figure 9 Correlation between the efficiency of differentiation into cardiomyocytes and cell surface $\mathbf{N}$-cadherin expression in human mesenchymal sten cell (MSC) lines.

The vertical axis represents the differentiation efficiency, while the horizontal axis represents cell surface expression of $\mathrm{N}$-cadherin. The correlation coefficient ( $\mathrm{r}$ ) is shown on the graph. 


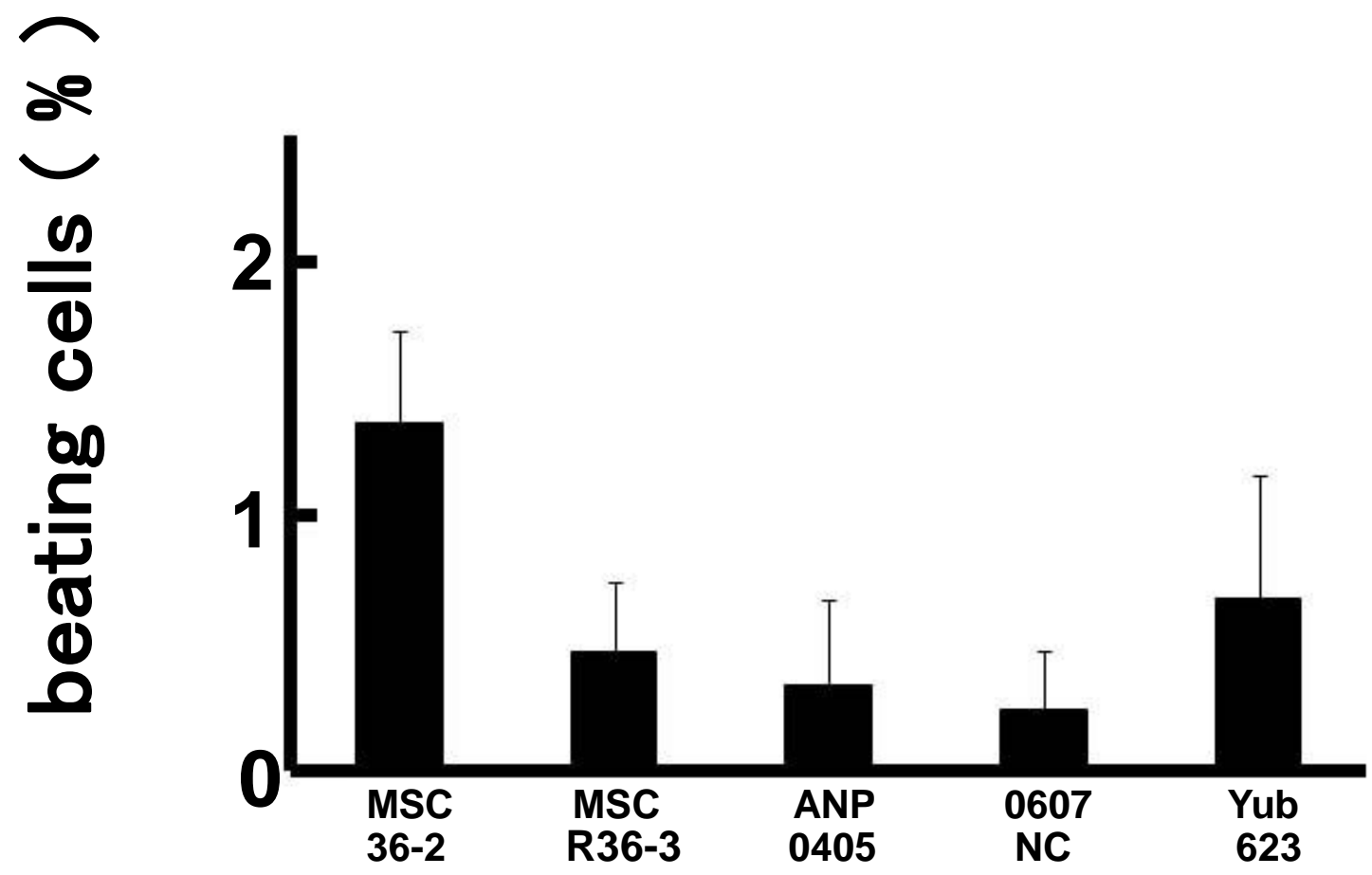

Figure 10 Efficiency of differentiation of primary human bone marrow-derived mesenchymal stem cells (BMSCs) into cardiomyocytes.

In this experiment, primary human mesenchymal stem cells (MSCs) derived from bone marrow (BMSCs) were used. Autonomously beating cardiomyocytes differentiated from GFP-labeled human BMSCs

were counted using a microscope. Bar graphs represent the mean values of the differentiation efficiencies obtained from more than two independent experiments. 


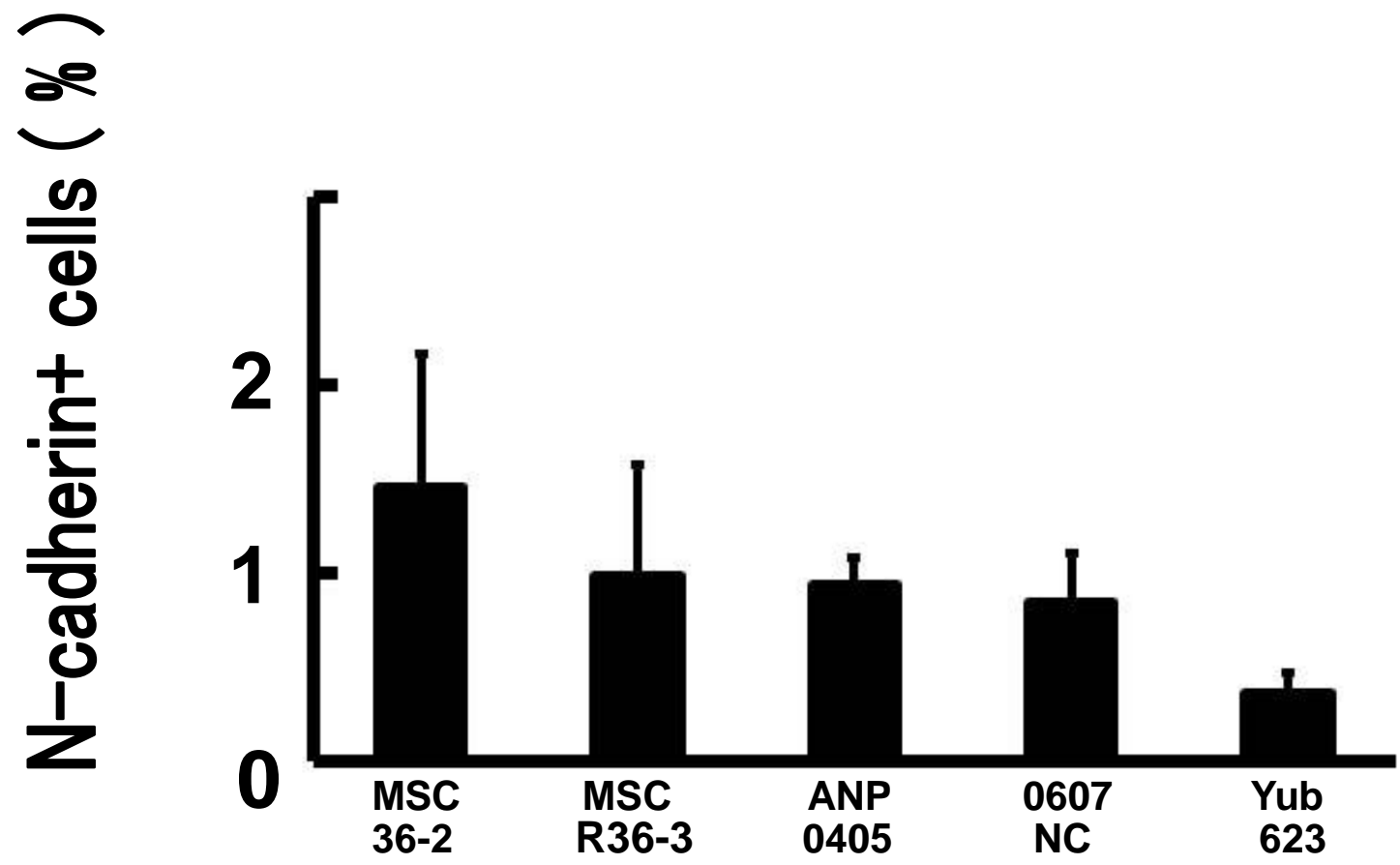

Figure 11 Cell surface expression of $\mathbf{N}$-cadherin.

Flow cytometric analysis of cell surface expression of $\mathrm{N}$-cadherin in primary human bone marrow-derived mesenchymal stem cells (BMSCs). Bar graphs represent the mean values of differentiation efficiency obtained from more than two independent experiments. 


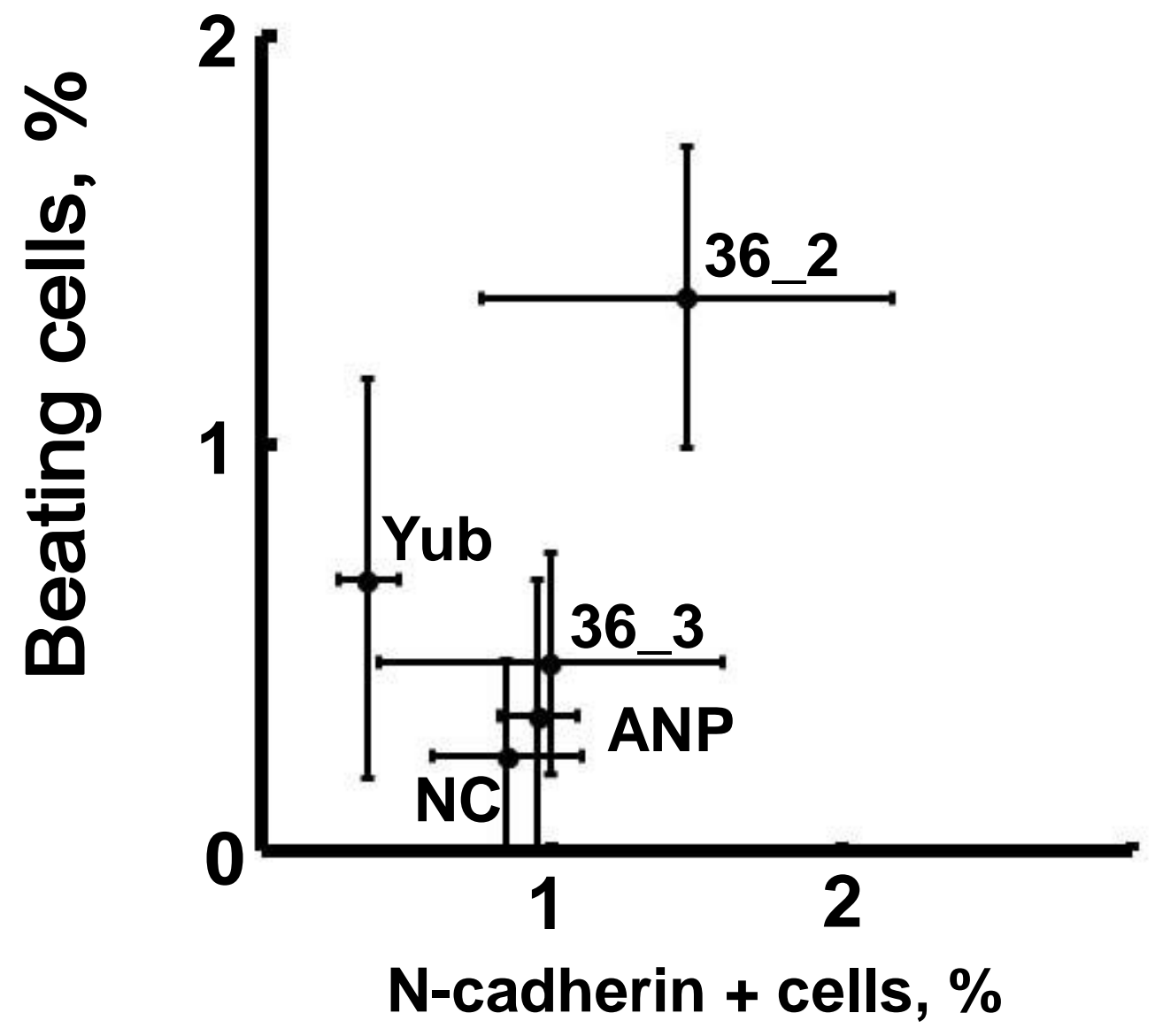

Figure 12 Correlation between the efficiency of differentiation into beating cardiomyocytes and the cell surface $\mathrm{N}$-cadherin expression of primary human bone marrow-derived mesenchymal sten cells (BMSCs).

The vertical axis represents the differentiation efficiency, while the horizontal axis represents cell surface expression of $\mathrm{N}$-cadherin. The correlation coefficient (r) is shown on the graph. 


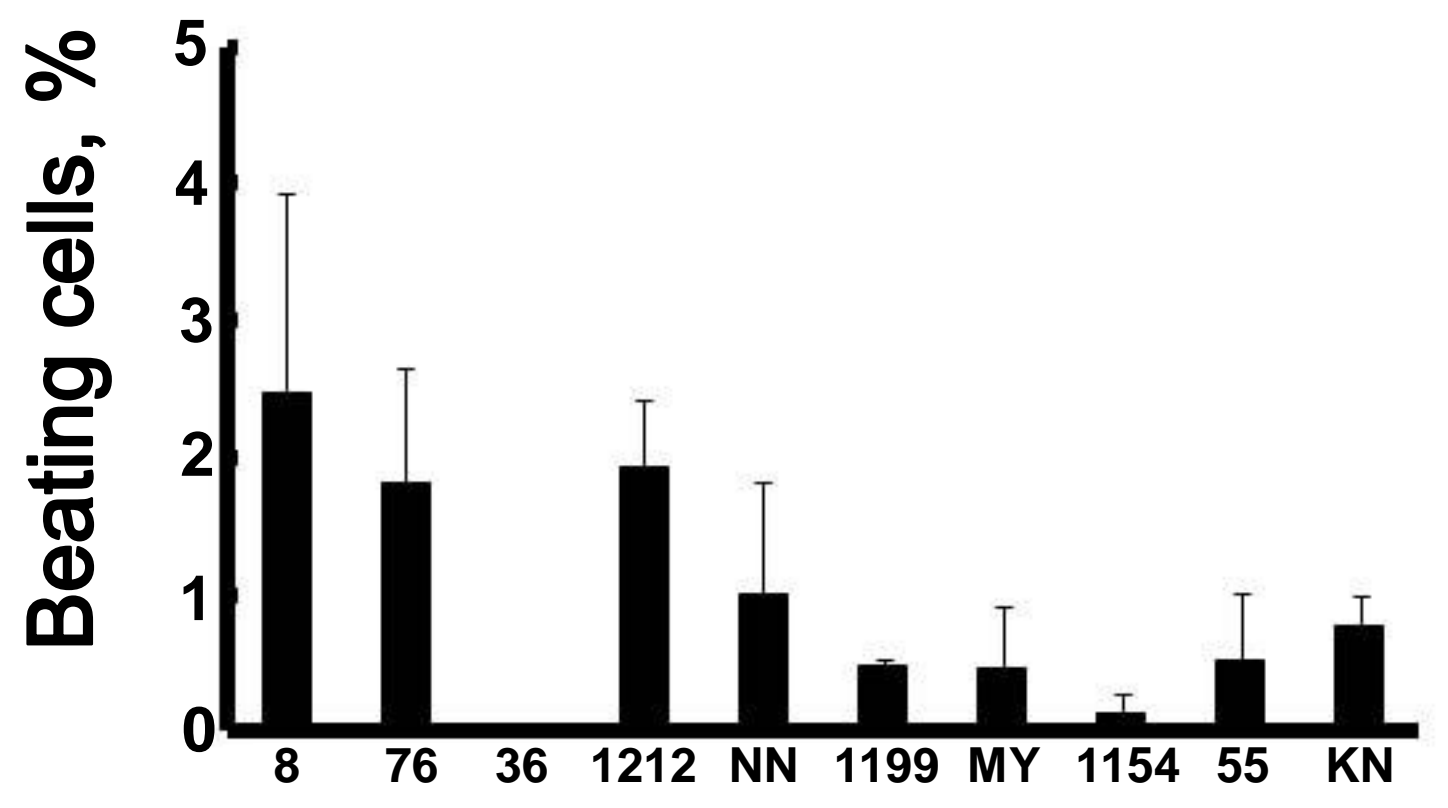

Figure 13 Efficiency of differentiation of primary human bone marrow-derived mesenchymal stem cells (BMSCs) into cardiomyocytes.

In this experiment, primary human MSCs derived from adipose tissue (ASCs) were used. Autonomously beating cardiomyocytes differentiated from GFP-labeled human ASCs were counted using a microscope. Bar graphs represent the mean values of the differentiation efficiencies obtained from more than two independent experiments. 


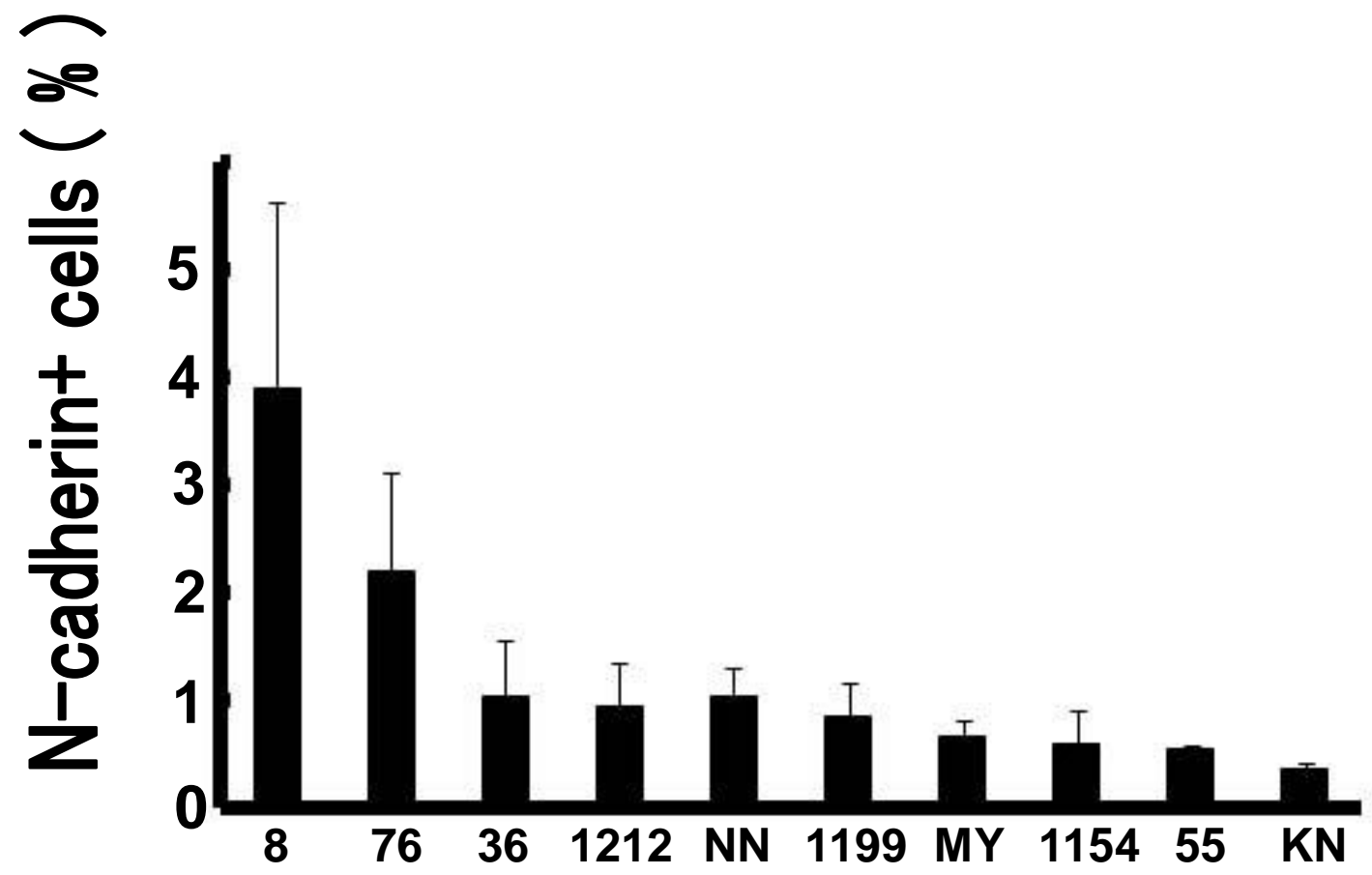

Figure 14 Cell surface expression of $\mathbf{N}$-cadherin.

Flow cytometric analysis of cell surface expression of $\mathrm{N}$-cadherin in primary human bone marrow-derived mesenchymal stem cells (BMSCs). Bar graphs represent the mean values of differentiation efficiency obtained from more than 2 independent experiments. 


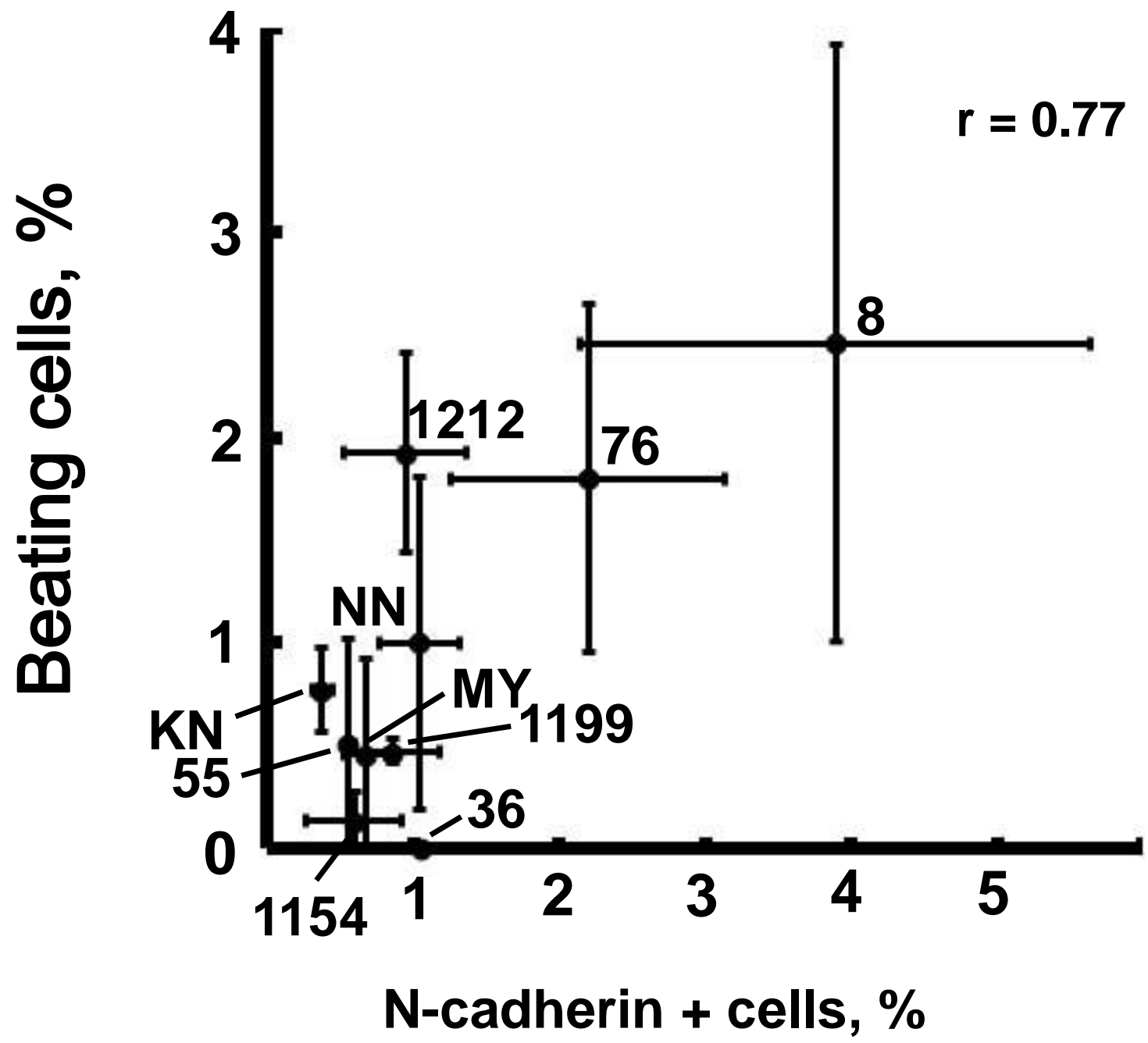

Figure 15 Correlation between the efficiency of differentiation into beating cardiomyocytes and cell surface $\mathrm{N}$-cadherin expression of primary human adipose -derived stem cells (ASCs).

The vertical axis represents the differentiation efficiency, while the horizontal axis represents cell surface expression of $\mathrm{N}$-cadherin. The correlation coefficient (r) is shown on the graph. 
A

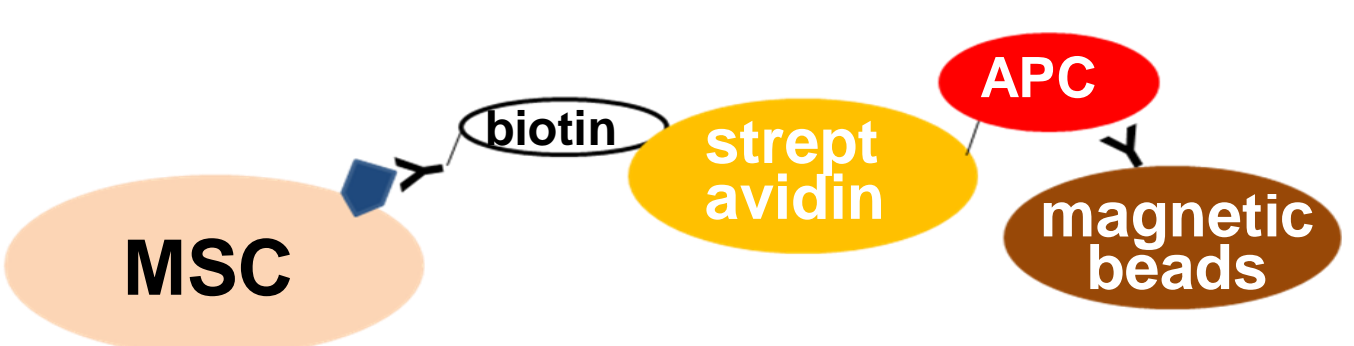

B

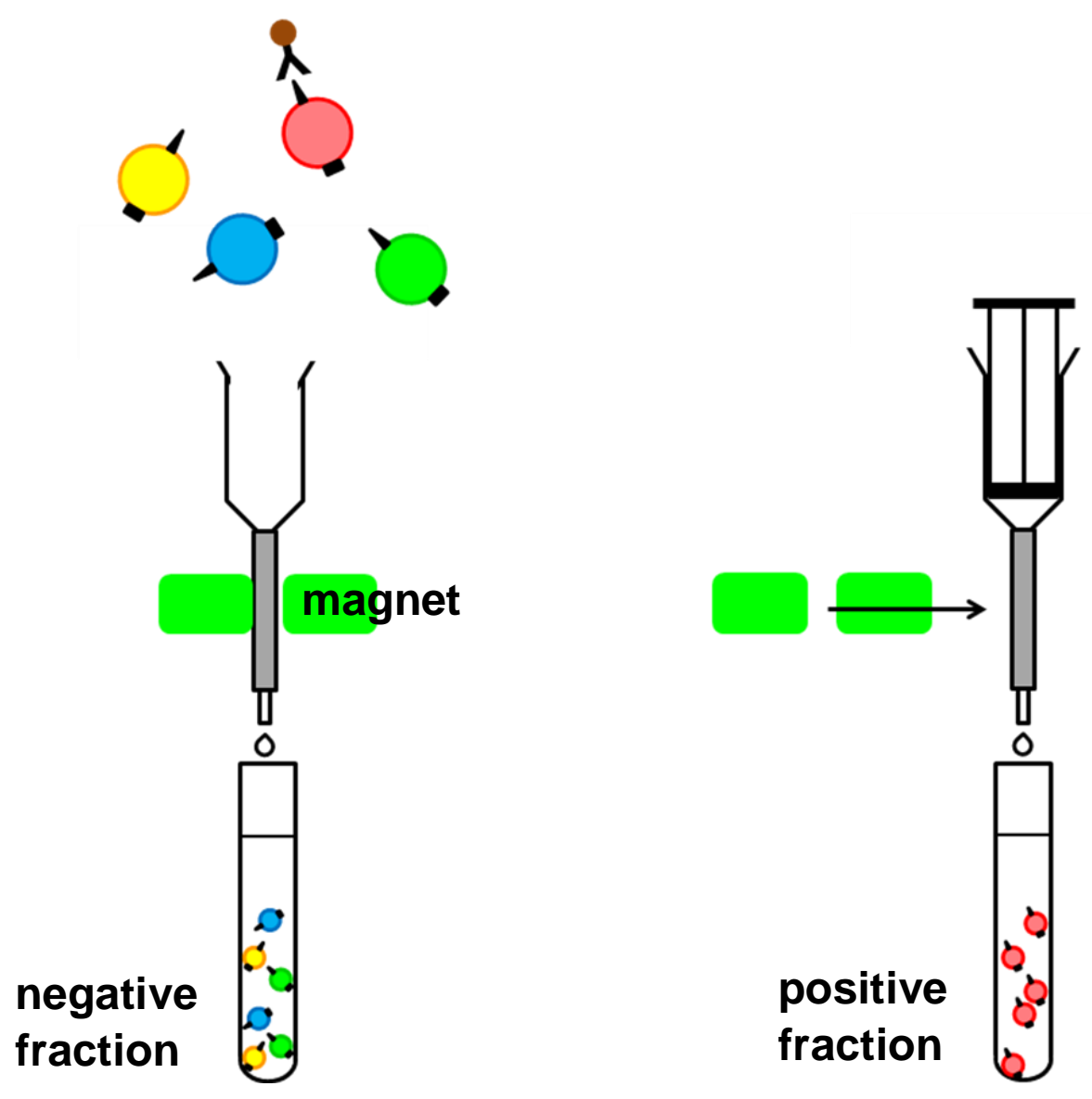

Figure 16 Schematic diagram of the magnetic cell sorting method

Human mesenchymal stem cells (hMSCs) were labeled with biotinylated anti-N-cadherin antibody. Next, hMSCs were incubated with streptavidin-APC. and anti-APC magnetic beads (A). Cell separation was performed on the Auto MACS Pro (B). 


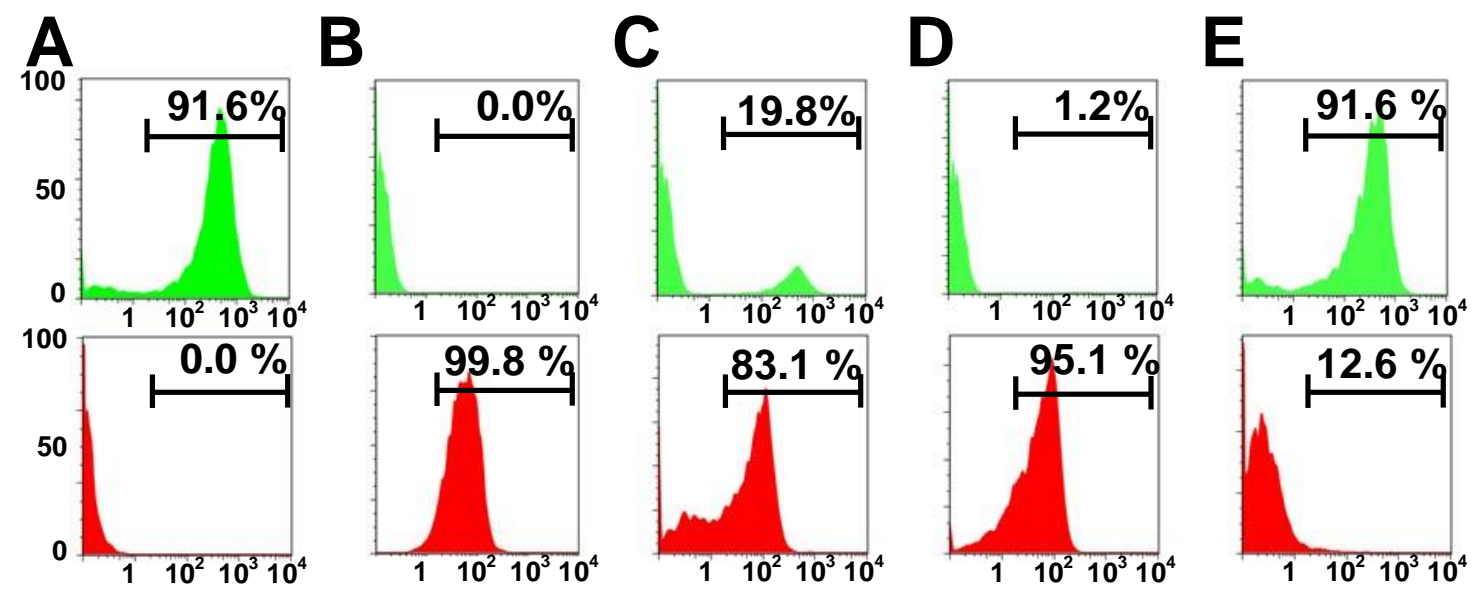

Figure 17 Demonstration of magnetic cell sorting.

$\mathrm{N}$-cadherin-positive cells were labeled by infection with GFP-expressing lentivirus (A) and $\mathrm{N}$-cadherin-negative cells were labeled with DDAO-SE dye (B). These cells were mixed (C) and sorted by using magnetic sorting technique. The $\mathrm{N}$-cadherin-negative fraction contained many DDAO-SE-positive cells (D), while the N-cadherin-positive fraction contained many GFP-positive cells (E)., 


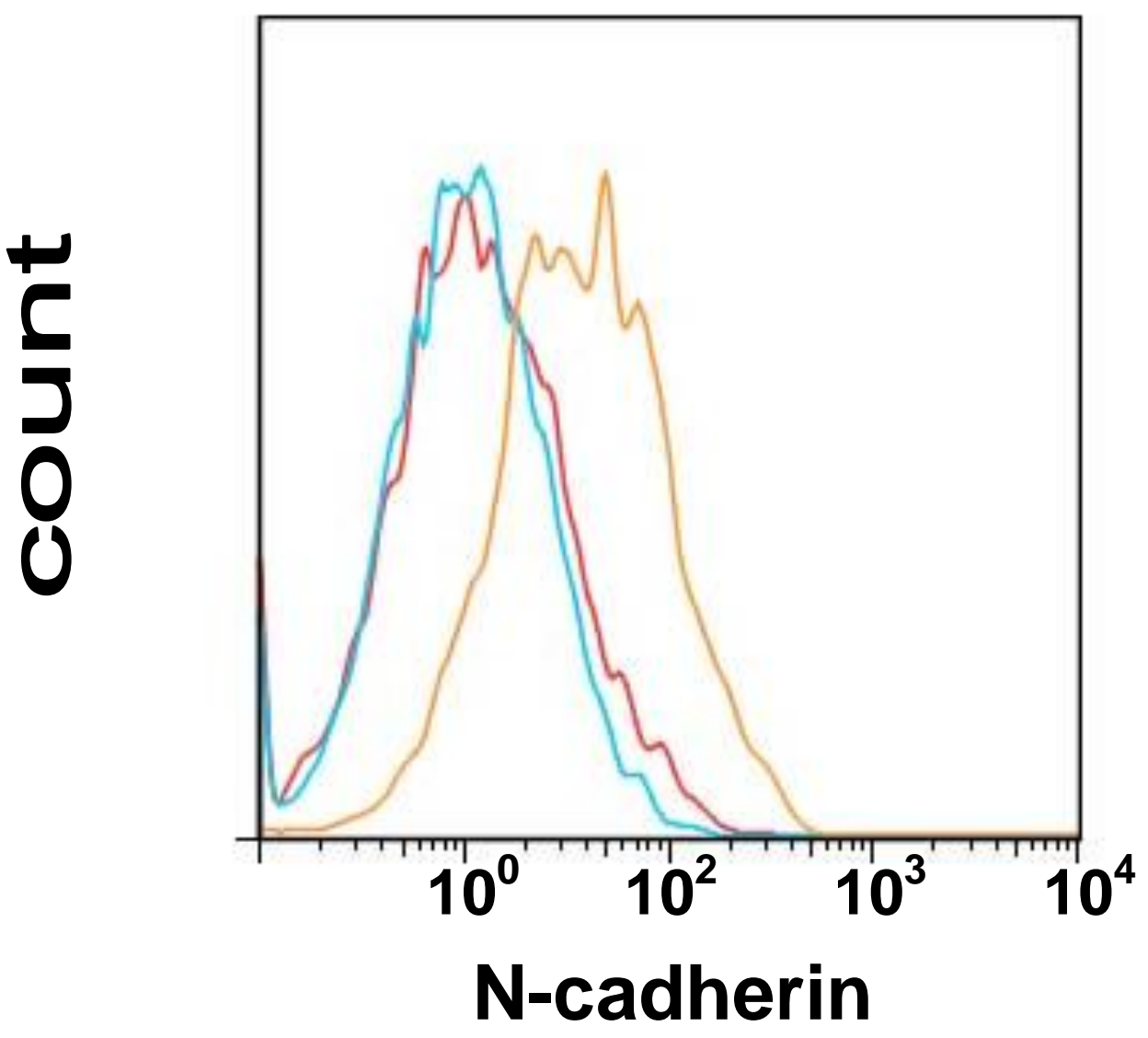

- ASC

- N-cadherin (-) fraction

- $\mathrm{N}$-cadherin (+) fraction

Figure 18 Separation of $\mathbf{N}$-cadherin-positive cells obtained from primary mesenchymal stem cells (MSCs) derived from adipose tissue with anti-N-cadherin antibody-conjugated magnetic beads.

The FACS histograms represent cell surface $\mathrm{N}$-cadherin expression in the $\mathrm{N}$-cadherin-negative fraction (blue) and $\mathrm{N}$-cadherin-positive fraction (orange). 


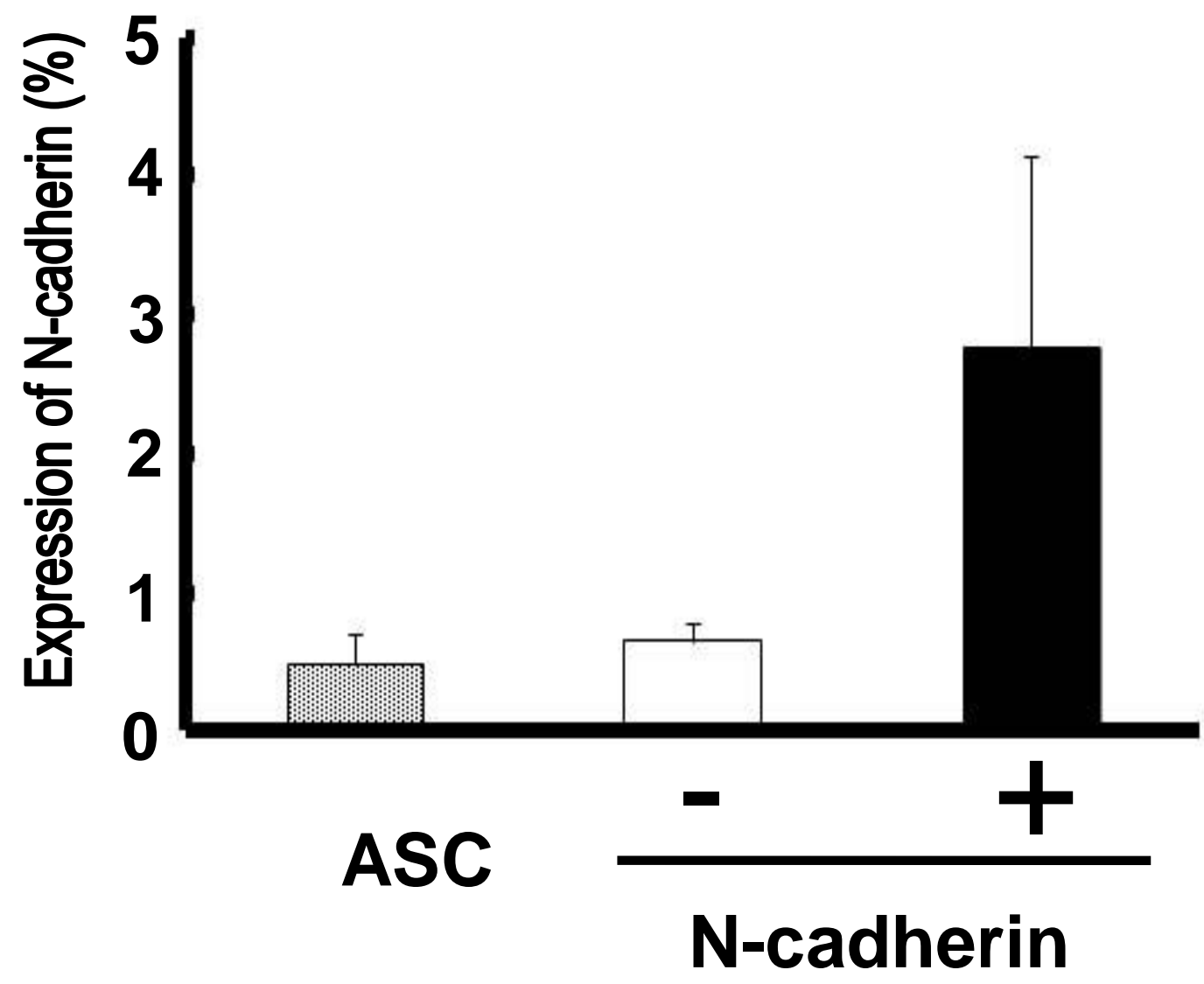

Figure 19 Expression of $\mathrm{N}$-cadherin in sorted mesenchymal sten cells (MSCs). These data were obtained by western blotting analysis. 


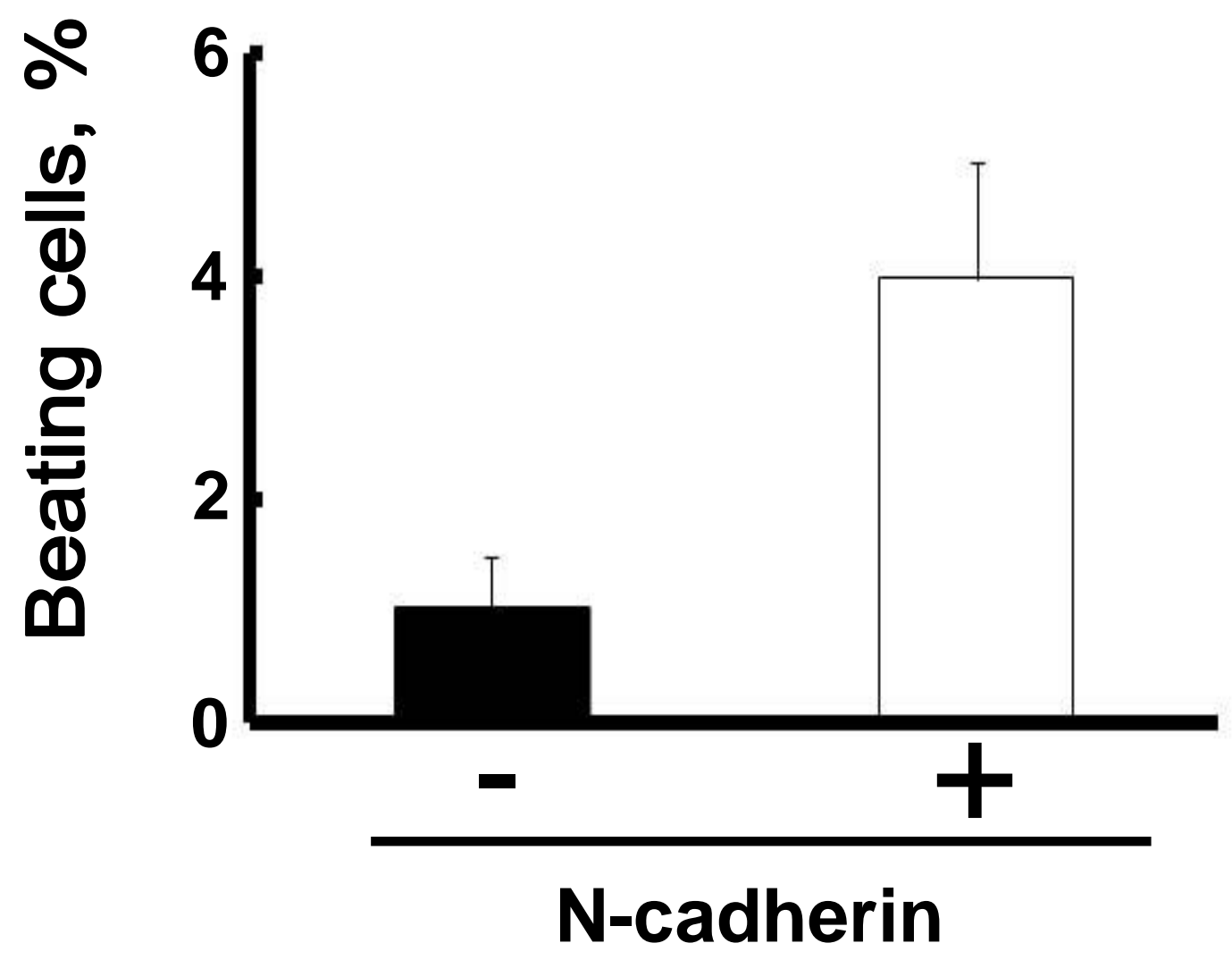

Figure 20 Efficiency of differentiation of purified primary adipose-derived stem cells (ASCs) into beating cardiomyocytes.

Bar graphs represent the mean value of differentiation efficiency obtained from 2 independent experiments. 


\section{MSC N-cadherin \\ MSC N-cadherin}

Pax4
Gata6
Gsc
Sox17
T
Ins
Flk1
Hnf4a
Mixl1
Foxa2
Cdh1
Cer1
Cxcr4
Alb
Gcg
Cyp3a4
Nes
Nefh
Eno2
Nefm
Nefl
Nckipsd
Sox2
Pax6
Calb1
Neurod6
Neurod1
Fabp7
Neurod4
Gfap
Dcx
Neurod2
Calb2
CD44
CD90
CD29
CD71
CD105
CD73
CD166
CD106
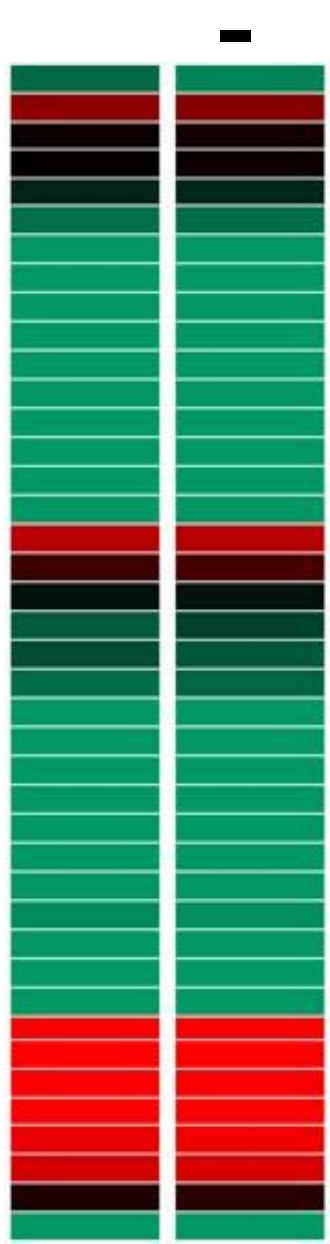
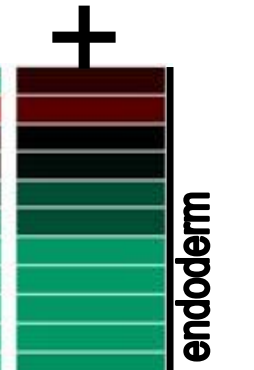

Ror2

$\mathrm{T}$

Ncam1

Mixl1

Col9a3

Bglap

Runx2

Spp1

Alpl

Col9a1

Col9a2

CD44

Col4a2

CD151

Col4a2

Sox 9

Acan

Col4a3

Col4a4

Col4a6

Col2a1

Col4a5

Cebpb

Cebpa

Pparg

Adipoq

Fabp4

Slc2a4

Lep

Myod1

Dmd

Myog

Nkx2.5

Hand1

$E=$ Mef2c

. Hand

등 $\mathrm{E}$ Nppa

\$ิ 탕

Tnnt2
Tbx5

\section{N-cadherin}
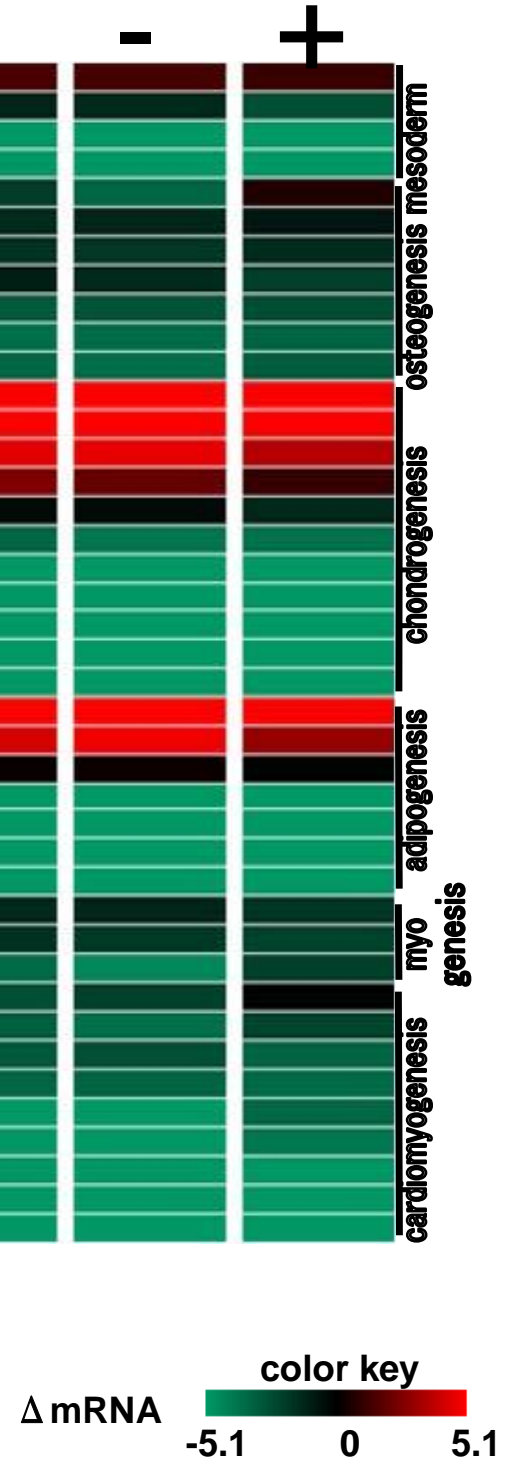

Figur. 21 Characterization of N-cadherin-positive cells derived from adipose tissue with anti-N-cadherin antibody-conjugated magnetic beads.

Heat map profile of lineage-specific differentiation marker expression in adipose-derived stem cells (ASCs). The N-cadherin-positive fraction showed elevated expression of specific genes involved in cardiomyogenesis 


\section{Nkx2.5 Gata4 Hand1 Tbx5 Myog}

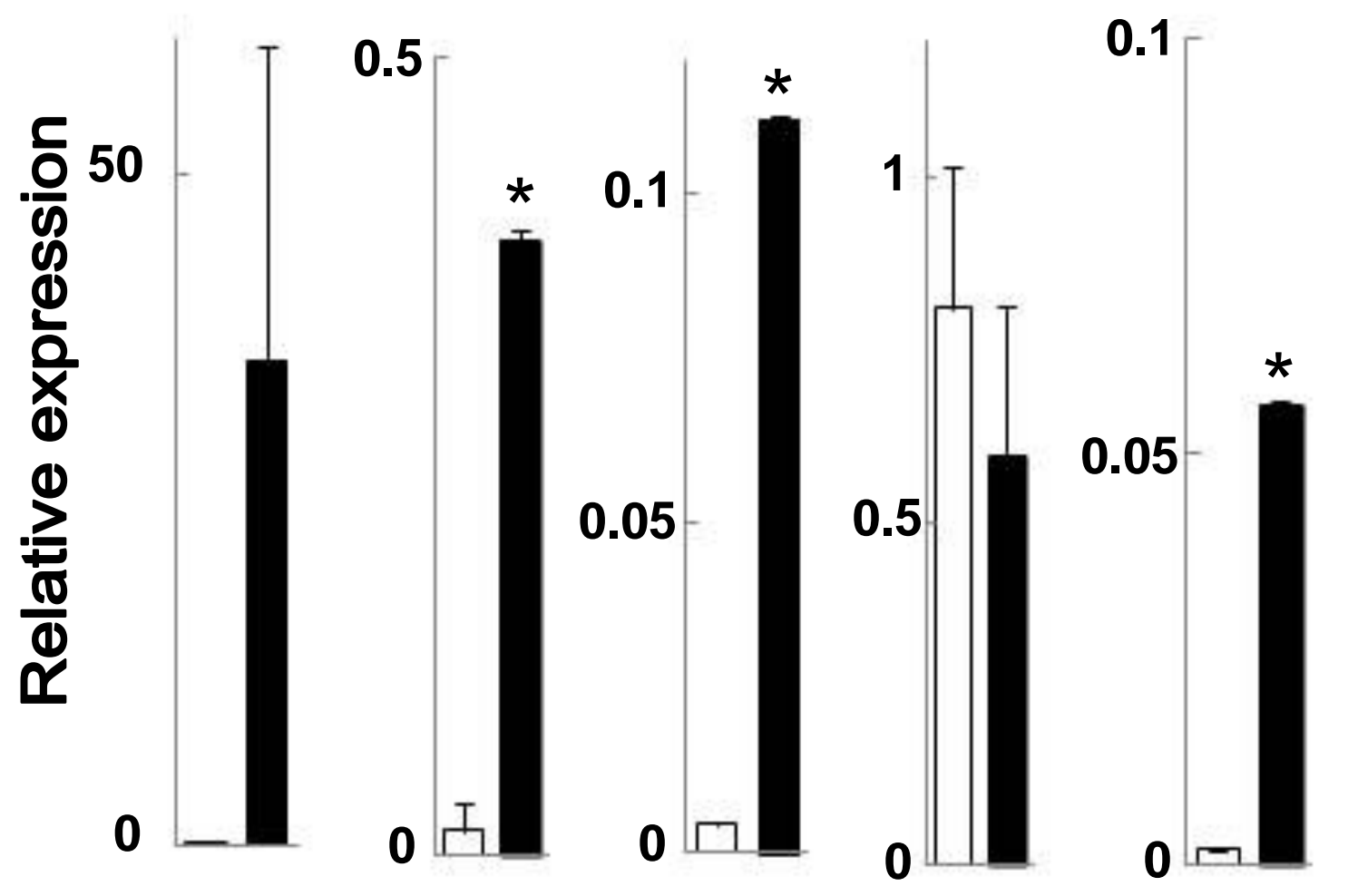

Figure 22 Quantitative polymerase chain reaction analysis of cardiomyogenic progenitor-specific transcription factors

White bar represent N-cadherin-negative cells. Black bar represent N-cadherin-positive cells.

Bar graphs represent the mean values obtained from 2 independent experiments. 


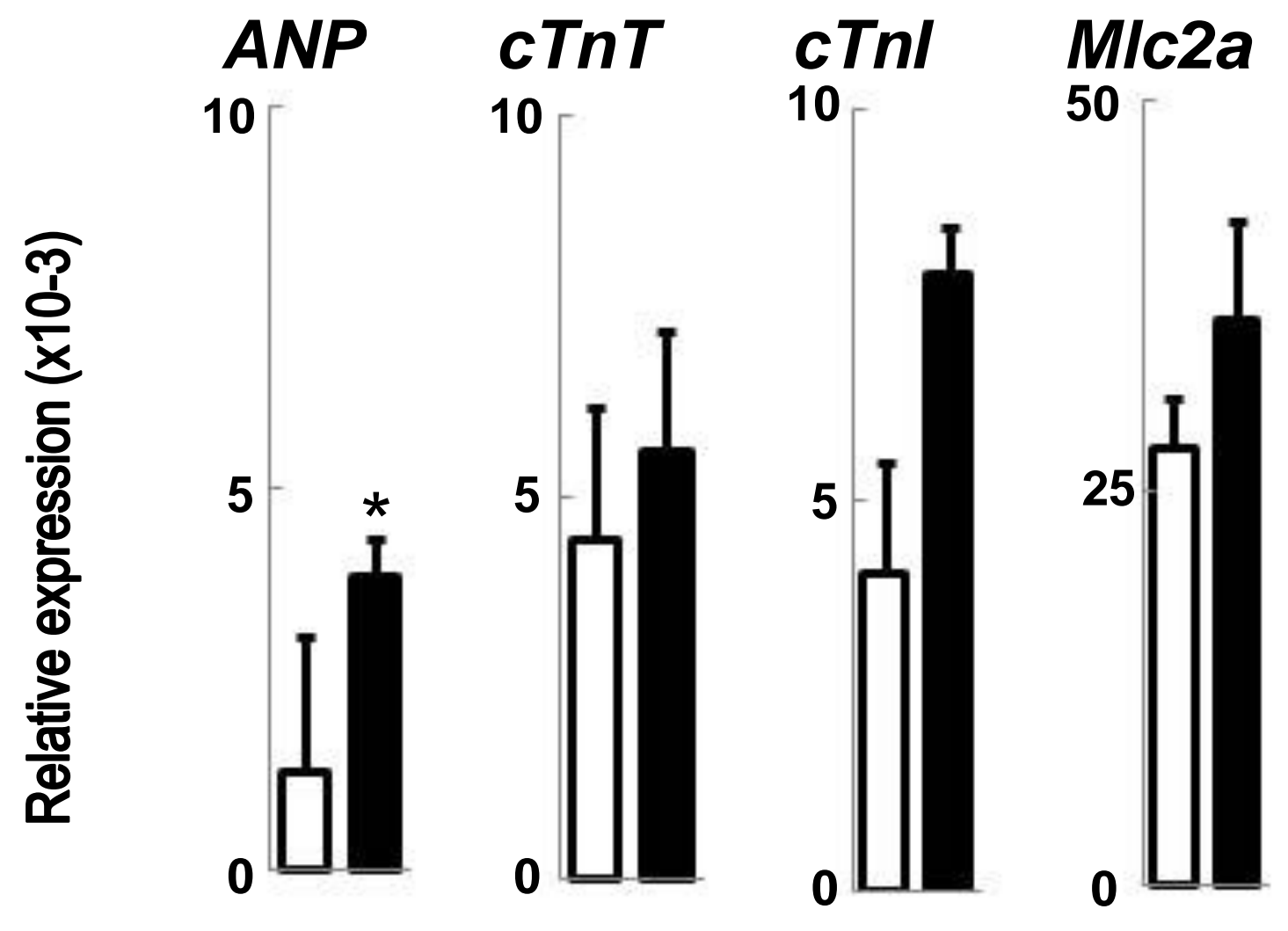

Figure 23 Quantitative polumerase chain reaction analysis of cardiomyogenic terminal differentiation markers

White bars represent N-cadherin -negative cells. Black bars represent N-cadherin-positive cells. Bar graphs represent the mean values obtained from 2 independent experiments. 

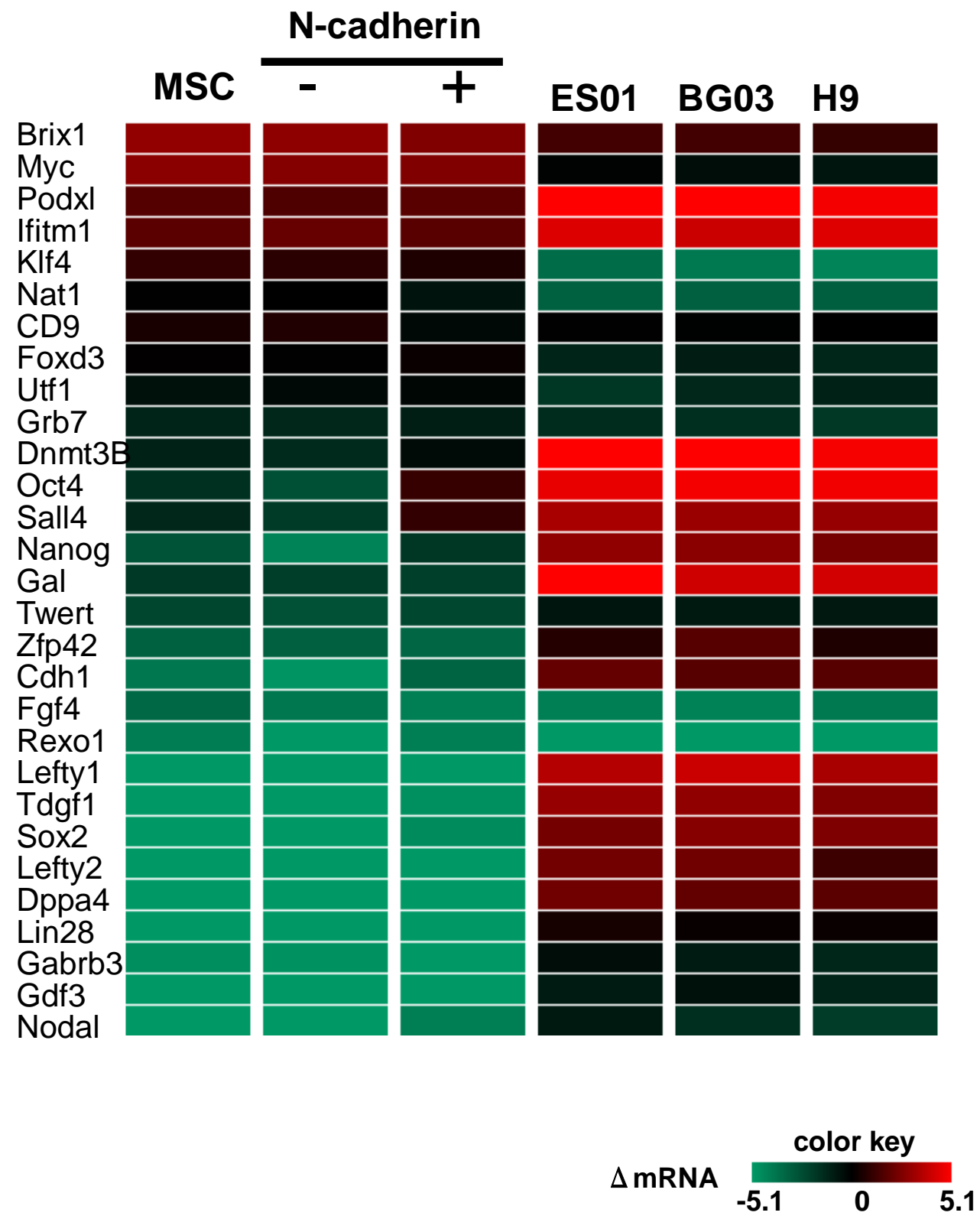

Figure 24 Characterization of $\mathrm{N}$-cadherin-positive cells derived from adipose tissue with anti-N-cadherin antibody-conjugated magnetic beads and human embryonic stem (ES) cells.

Heat map profile of pluripotency-specific marker expression in human adipose-derived stem cells (ASCs) and human ES cells. 


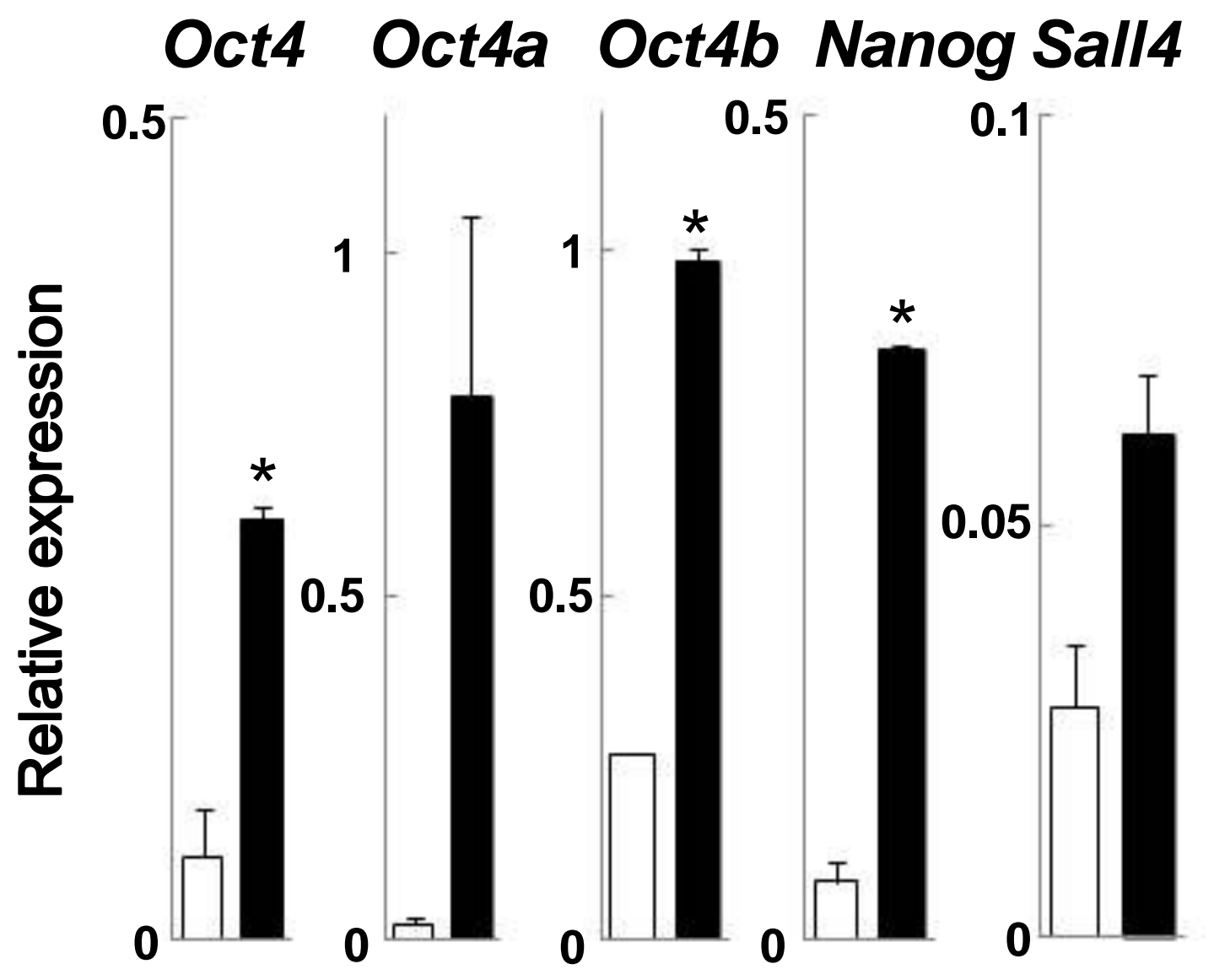

Figure 25 Quantitative polymerase chain reaction analysis of the expression of pluripotency-specific transcription factors in MACS-sorted fractions.

White bars represent N-cadherin-negative cells. Black bars represent N-cadherin-positive cells. Bar graphs represent the mean values obtained from 2 independent experiments. 